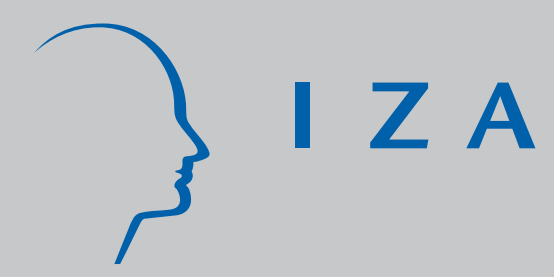

IZA DP No. 3450

International Migration, Ethnicity and Economic Inequality

Martin Kahanec

Klaus F. Zimmermann

April 2008 


\title{
International Migration, Ethnicity and Economic Inequality
}

\author{
Martin Kahanec \\ IZA \\ Klaus F. Zimmermann \\ $I Z A$, University of Bonn and DIW Berlin
}

Discussion Paper No. 3450

April 2008

IZA

P.O. Box 7240

53072 Bonn

Germany

Phone: +49-228-3894-0

Fax: +49-228-3894-180

E-mail: iza@iza.org

Any opinions expressed here are those of the author(s) and not those of IZA. Research published in this series may include views on policy, but the institute itself takes no institutional policy positions.

The Institute for the Study of Labor (IZA) in Bonn is a local and virtual international research center and a place of communication between science, politics and business. IZA is an independent nonprofit organization supported by Deutsche Post World Net. The center is associated with the University of Bonn and offers a stimulating research environment through its international network, workshops and conferences, data service, project support, research visits and doctoral program. IZA engages in (i) original and internationally competitive research in all fields of labor economics, (ii) development of policy concepts, and (iii) dissemination of research results and concepts to the interested public.

IZA Discussion Papers often represent preliminary work and are circulated to encourage discussion. Citation of such a paper should account for its provisional character. A revised version may be available directly from the author. 
IZA Discussion Paper No. 3450

April 2008

\begin{abstract}

\section{International Migration, Ethnicity and Economic Inequality ${ }^{\star}$}

While the allocative efficiency of mobility is typically considered to be positive but small in the long run, the induced changes in equality may be considerable in size. In practice, however, migrants typically improve their income position in comparison to those at home, stimulate the economic situation of the sending countries through remittances and rise the economic performance of natives and of capital in the host country through complementarities. The chapter suggests that at least skilled immigration promotes economic equality in the host country under standard conditions. The context is empirically documented und theoretically explained in a core model. Also, immigrant assimilation and selection is discussed, as is the role of ethnicity and ethnic identity for relative economic performance.
\end{abstract}

JEL Classification: D33, D63, E25, F22, F24, J15, J61, O15

Keywords: inequality, income distribution, migration, ethnicity, minority, assimilation, integration, ethnosizing, Gini-coefficient

Corresponding author:

Klaus F. Zimmermann

IZA

P.O. Box 7240

53072 Bonn

Germany

E-mail: Zimmermann@iza.org

\footnotetext{
Financial support from Volkswagen Foundation for the IZA project on "The Economics and Persistence of Migrant Ethnicity" is gratefully acknowledged. We thank Deborah A. Cobb-Clark, Amelie F. Constant, Stephen J. Nickell, Brian Nolan, Wiemer Salverda, Timothy M. Smeeding and Mutlu Yuksel for helpful comments on earlier drafts. This is a draft chapter to appear in Wiemer Salverda, Brian Nolan, and Timothy M. Smeeding, eds., Oxford Handbook on Economic Inequality, Oxford: Oxford University Press, forthcoming 2009.
} 
"Our review of economic research finds immigrants not only help fuel the Nation's economic growth, but also have an overall positive effect on the income of native-born workers."

US Council of Economic Advisers Chairman Edward P. Lazear

\section{Introduction}

International and national migration is a momentous phenomenon driving the fortunes of large numbers of people. ${ }^{1}$ The issue of labour flows is also an important part of any textbook in economics. Why do people move, and what happens to their welfare and that of the receiving and sending countries when they do? A widely accepted answer is that immigration helps to achieve a more efficient allocation of resources, and hence improves the welfare of nations. However, the rise in allocative efficiency is often considered to be fairly small. ${ }^{2}$ The controversy starts with concerns about the distributional effects of immigration: (i) Is immigration detrimental, that is, do immigrants depress the wages and increase the unemployment of the natives, often enter into poverty within the receiving countries, and deprive the sending regions of their most motivated and talented workers? (ii) Is it possible that immigration is just not large and significant enough to cause such damage to be noticeable? Or: (iii) Is immigration de facto beneficial, because most empirical studies fail to identify any negative effects on the natives, immigrants are typically faring better in the receiving countries than at home, and the sending countries' population benefits from remittances and labour force from the induced scarcity in the home labour markets? And: (iv) What is actually the objective, equality among natives or among natives and immigrants together?

This chapter uses a well-defined setting to suggest an optimistic view about the distributional effects of immigration. We apply well-established concepts from the allocative debate to investigate the inequality issues, and extend the analysis to cover the role of ethnicity and ethnic

\footnotetext{
1 According to United Nations (UN) estimates, the share of international migrants in the total world population was 2.4\% in 1965, 2.3\% in 1985 and reached 3.0\% in 2005. In more developed regions, including Europe, Northern America, Australia, New Zealand and Japan, the corresponding share reached 9.5\% in 2005. See United Nations, Department of Economic and Social Affairs, World Migrant Stock: The 2005 Revision Population Database.

${ }^{2}$ See Borjas (1999b) for equilibria situations. However, Bauer and Zimmermann (1997) have pointed out that the increase or decrease in allocative efficiency can be very large under particular disequilibrium conditions.
} 
identity for the labour market. For the empirical part, we use data from the OECD countries. Conceptually, we adopt the "no-job, job, good job"-approach to the concept of economic inequality and the "unskilled-skilled paradigm" of labour migration. We study the issues of economic absorption (or assimilation) over time and across generations and consider selection through immigration and emigration choices and immigrant admission policies. We further deal with the impacts of ethnic identity on economic performance, and hence inequality.

Section 2 provides a general picture of the native-immigrant differences in labour force participation, unemployment, and occupational and educational attainment, controlled for skill levels and years since immigration. Section 3 investigates the inequality impact of immigration by summarizing the potential labour market impacts and the wage and employment consequences. Assuming immediate and full adjustment of immigrants, our stylized model suggest that skilled immigration is largely positive for the host economy, as inequality measured by the Gini coefficient improves with it for the most part. This model conjecture is supported by empirical evidence. Section 4 deals with the potentially slow integration of immigrants into the labour market of the host country, as well as with the role that self-selection and selection through politically set admission rules can play for the performance in the labour market. We also consider cultural or ethnic identity as an independent factor of economic success and discuss the consequences for inequality. Section 5 concludes.

\section{Some Empirical Facts}

The empirically measured association between inequality and the presence of immigrants in the economy reflects many aspects of mutual influence. On the on hand, migrants carry different amounts and forms of capital with them and represent different types of labour, thereby directly affecting the distribution of income in host societies. Furthermore, they have an indirect impact through changing the productivity of incumbent production factors as well as impinging on the redistributive policies in the host societies. On the other hand, different migrants select into 
countries with different degrees of inequality. As shown in Table 1, New World countries with a high share of foreign-born population, such as the US or Australia, also have higher income inequality. Post-transition OECD country members, such as Poland or Slovakia, have very low shares of foreign population and low Gini coefficients. Western European countries are in between.

This comparison is misleading, however. The three groups of countries differ in terms of their economic institutions, redistribution policies, as well as the nature, type, and history of immigration. For example, the post-transition countries have low inequality and low shares of foreign population due to their history as closed command economies. The New World countries, at the other end of the spectrum, have a history of liberal immigration and economic policies. Therefore, it is appropriate to deal with these groups of countries separately to characterize the relationship between inequality and immigration.

In Figure 1 we therefore concentrate on European countries that share similar histories of immigration and economic institutions, focusing on the relationship between the Gini coefficient and the share of foreigners in the labour force. We observe no clear-cut relationship. In Figure 2, however, when we drop the outlier countries Luxembourg and Switzerland, the predicted values of a line plot of the nonparametric locally weighted regression of Gini values on the share of foreign labour suggest a distinct negative relationship. But such a finding could be affected by the quality composition of the foreign labour force. Only if it were the same across countries, one might safely predict declining inequality with rising shares of foreign labour.

Therefore, to identify some of the key mechanisms driving the relationship between immigration and labour market inequality we focus on three specific integration issues that govern the economic success of immigrants. First, labour market participation rates of the working age immigrant population characterize the economic activity of immigrants and their earnings prospects. Second, immigrants' unemployment rates mirror immigrants' chances of being employed and measure immigrants' earnings prospects conditional on their labour market participation. Third, 
the occupational attainment of immigrants depicts immigrants' chances to obtain well-paid jobs, conditional on employment.

While a number of member states of the European Union $^{3}$ (EU) are still significantly behind the employment objectives stipulated in the Lisbon Agenda ${ }^{4}$, the standing of immigrants is often even more adverse in many respects. This disparity suggests to use natives as a benchmark and to identify to what extent immigrants integrate in terms of their labour market outcomes and attain the Lisbon Agenda targets. There are a number of factors that determine individual economic attainment and drive the economic gap between immigrants and natives. Among these, perhaps the most significant one is human capital. Immigrants' labour market success is a function of their skills as well as the transferability of their skills into the new economic environment of the destination country. Furthermore, as immigrants face new incentives to adjust and invest in skills specific to their new economic environment, such as acquisition of language skills, the time that they have spent in the host country matters for their economic attainment.

We report here statistics for the working age population on labour market participation, unemployment and occupational attainment for the categories natives, immigrants with at least 10 years of experience in the host country, immigrants in general, and three skill categories for both natives and immigrants pooled together defined as third (high), upper secondary (medium), and lower secondary (low) level of highest educational attainment. ${ }^{5}$ We consider EU25 as a whole and the traditional European destination countries (EU15) separately to highlight some of the salient

\footnotetext{
${ }^{3}$ For a detailed discussion of the Lisbon strategy see Sapir et al. (2004), for instance.

${ }^{4}$ Set out in March 2000, the Lisbon Agenda of the EU stipulates, among other ambitious targets, that the overall employment rate and the female employment rate, which reflect the abovementioned participation and unemployment margins, should reach $70 \%$ and 60\%, respectively, by 2010 .

${ }^{5}$ Statistics are based on the EU Labour Force Survey 2005. High level of education includes ISCED 5 and 6 levels. ISCED 5 denotes first stage tertiary programmes having an educational content more advanced than those offered by secondary levels. They do not lead to the award of an advanced research qualification and must have a cumulative duration of at least two years. ISCED 6 denotes second stage tertiary education leading to an advanced research qualification and requiring original research contribution in the form of a thesis or dissertation. Medium level of education includes ISCED 3 and 4 levels, which denote education that typically begins at the end of full-time compulsory education and involves higher qualification and specialization than the ISCED 2 level. ISCED 3 level education is often designed to provide direct access to ISCED 5. ISCED 4 serve to broaden the knowledge achieved in ISCED 3 but are not regarded as tertiary. Low level of education includes ISCED 0, 1, and 2 levels. These include pre-
} 
stylised patterns of immigrant-native labour market gaps and the role of human capital and adjustment in driving these gaps. ${ }^{6}$

Table 2 reports the participation rates. The rates of the natives vary between $45.29 \%$ in Italy and $78.45 \%$ in Sweden. In Netherlands and Sweden, the immigrants have fairly similar rates as the natives, although the natives rank first, followed by the immigrants with long-term presence and the immigrants in general. This is consistent with the hypothesis that immigrants need some time to assimilate to the labour market and to adjust to the natives' way of working or living. The numbers for Austria, Spain, Ireland, Italy and Luxembourg suggest the opposite: Immigrants have higher participation rates than natives, and these rates seem to be even higher for newcomers. This observation is consistent with the selection hypothesis, whereby it is the people with strong labour market potential, economic motives, and a desire to work who migrate. They only slowly adapt to the lower participation levels of the natives.

Another interpretation is based on cohort effects: In the 1960s and early 1970s immigrants in Western and Northern Europe were labour migrants selected to work through immigration policies. After the 1973 general halt on recruitment there were periods of political and refugee immigration as well as family-reunification, resulting in migrants with lower work incentives. Southern Europe and Ireland turned into immigration destination areas only in the last decade, where stronger growing economies and the opening of the Eastern Bloc were attracting larger numbers of labour immigrants. Such cohort effects may also explain the situation in Germany, the UK, France, and other countries where immigrants with long-term presence have lower participation rates than their recent counterparts (or natives). In these countries, however, immigrants are less active than the natives. This observation may reflect negative selection of immigrants to these countries. In Portugal, Greece, Finland, Denmark, and EU25 as a whole immigrants are more active than natives, especially if they have been in the respective economy for the end of compulsory schooling where it exists. For further details see UNESCO (1997). 
more than 10 years. Such finding may be due to positive selection and beneficial effects of experience in the destination country, as discussed above.

A consistent picture across the columns of Table 2 is that educational levels and participation rates are positively associated. That is, more educated individuals exhibit much higher labour market participation rates than lower educated individuals. In general, immigrants in Europe are much less educated than in the US or Australia. In some European countries, this has been fostered for many decades by the immigration policies outlined above that had also focused on the immigration of blue-collar workers before the recession in 1973.

Table 3 contains the unemployment rates. The results here provide a clear-cut picture: Tenure in the country and education do matter; they are associated with lower unemployment rates. ${ }^{7}$ New immigrants have higher unemployment rates than natives and than those immigrants who are longer in the host country, which is consistent with the assimilation hypothesis of slow adaptation to the host labour market. In comparison to the natives, immigrants do particularly poorly in Belgium, Finland and Germany, and fairly well in Greece, Luxembourg, Portugal and Spain. ${ }^{8}$ Immigrants' $^{\prime}$ unemployment rates are about the same as those of all the low educated for e.g. the EU25 and Spain, but substantially larger for Finland and the Netherlands.

Table 4 summarizes the occupational attainment of immigrants. Similarly to the participation picture, occupational attainment ${ }^{9}$ exhibits a mixed pattern. While in most countries natives do significantly better than immigrants, in the UK and Portugal immigrants' attainment is higher. Tenure in the destination country pays off especially in Spain, Ireland and Denmark, where it actually helps immigrants to outperform the natives. The occupational attainment of the low educated is below that of the immigrants, and close only in the case of Spain and Greece.

\footnotetext{
${ }^{6}$ EU denotes the 25 member states of the European Union in 2005 except for Malta for which no data is available. Romania and Bulgaria joined the EU in 2007 and are not included. EU15 denotes the 15 member states prior to the 2004 enlargement.

${ }^{7}$ The only exception is Greece, where experienced immigrants have higher unemployment than more recent immigrants. Nevertheless, natives do better than immigrants.

${ }^{8}$ Measured by the unemployment rate gap.

${ }^{9}$ At least rank 3 of the ISCO88 classification (1: Legislators, senior officials, and managers; 2: Professionals; 3 : Technicians and associated professionals). For further details see ILO (1990).
} 
The educational composition of immigrants might explain the observed native-migrant labour market gaps. Table 5 provides only limited support for this conjecture. While immigrants are on average less educated than natives in some countries, including France and the Netherlands, in the EU25 as a whole and in a number of countries the evidence is less conclusive as the percentage of highly educated individuals is highest among immigrants. We can conjecture that the differences in education do not sufficiently explain differences in labour market outcomes between natives and immigrants.

Considering the other OECD countries, in the United States the foreign born population had a higher participation rates than the natives (67.7\% against 65.8\%) and lower unemployment rate (4.6\% against $5.2 \%$ ) in $2005 .{ }^{10}$ This finding may reflect positive selection of immigrants into the US and the liberal institutions that reward active participation in the labour market. The evidence is fairly mixed in the post-transition OECD members, perhaps due to the short history of immigration. ${ }^{11}$ While participation rates are for the most countries smaller for immigrants, the unemployment rates are higher in the Czech Republic and Slovakia, lower in Poland, and almost equal in Hungary. The Australian experience highlights the role of institutional immigrant selection mechanisms. Table 6 reveals that (i) tenure in Australia in general is positively associated with immigrants' participation and negatively with their unemployment rates, (ii) immigrants through streams that select on skills and economic aptitude perform better than those who came through other streams, and (iii) immigrants who faced more stringent immigration rules in 1999 and 2000 perform better than the cohorts of the early 1990s.

The presented empirical observations suggest that immigrant adjustment is an important factor driving immigrants' labour market outcomes vis-à-vis the native population. While experience in the host society seems to reduce the observed gaps, it may also dissipate the positive effects of self-selection of economic immigrants on participation rates in some countries. The

\footnotetext{
${ }^{10}$ The data are from the 2005 US Bureau of Labor Statistics.

${ }^{11}$ We base this on unreported statistics from the 2005 EU Labour Force Survey.
} 
changing composition of immigrant flows often due to policy changes may be another important factor driving the immigrant-native labour market gaps. While education is shown to be an important determinant of labour market outcomes, it does not seem to be the sole driver of the observed gaps.

\section{The Inequality Impact of Migration}

\section{A Literature Review}

International flows of people fuel relocation of production factors and wealth attached to migrants and thus affect the allocation of the world income. Zlotnik (1999) and Chiswick and Hatton (2003) report that migrant flows to the developed countries have increasingly involved migrants from less developed countries. Besides the effects on the international world income inequality, these migration flows affect intra-national income distribution in sending and receiving countries.

The literature on the effects of emigration on various measures of inequality in sending rural areas of poor countries dates back to Lipton (1977), who argues that such emigration increases interpersonal and inter-household inequality within and between rural villages. A number of studies addressing this issue in national and international settings, such as Stark, Taylor and Yitzhaki (1986, 1988), Taylor (1992), Adams (1989, 1992), Lipton (1980), Stahl (1982), Barham and Boucher (1998) and McKenzie and Rapoport (2006), portray a mixed picture, where the direction of these effects depends on applied methodologies, type of migration, and stages of the studied migration histories. To illustrate, Stark, Taylor and Yitzhaki (1986) found that remittances from emigrants assuage income inequality in a Mexican village with an extensive experience of emigration to the US. Stark, Taylor and Yitzhaki (1988) examine the sensitivity of the estimated positive effect of remittances from the US on a Mexican village using an extended Gini index of inequality. They find that this effect decreases as incomes of people at the bottom of the distribution are assigned higher weights. In contrast, Adams (1989) finds that remittances increased inequality in three Egyptian villages comparing the actual migration history to the no migration counterfactual. 
Replicating the study for four Pakistani villages, he finds neutral effects (Adams, 1992), however. Barham and Boucher (1998), find that migration reduces inequality assuming exogeneity of remittances, while finding the opposite effects when endogeneity of remittances is accounted for.

The impact of immigration on the destination labour market has been modelled by a number of studies, including Chiswick, Chiswick and Karras (1992) and Chiswick (1980, 1998). In these models, the effects of migration on income inequality in receiving countries largely depend on the socio-economic and demographic characteristics of the immigrant and native populations as manifested by the substitutability or complementarity of their labour. Concerning the empirical evidence, for the US, Grossman (1982) finds that foreign-born workers are substitutes for native workers and Borjas (1983) reveals complementarity between Black and Hispanic labour and Hispanic and White male workers. Borjas (1987a) provides some evidence that White, Black, Hispanic, and Asian immigrant male workers are substitutes for Whites born in the US. All these studies report effects of small magnitudes.

However, more recent studies provide evidence of diverse and non-negligible labour market effects of immigration. Using data from the 1990 US census, Card (2001) distinguishes the effects of immigration for various occupational groups and finds significant negative employment effects in most cases. In a similar study, Orrenius and Zavodny (2007) find negative wage effects of immigration on unskilled natives but do not find significant effects in skilled occupations. Borjas, Freeman and Katz (1997) report that immigration explains a significant proportion of the increase in the wage gap between high and low skill labour in the US in the 1980s and early 1990s. Negative wage effects of immigrants on their co-ethnics in the same linguistic group are reported by Chiswick and Miller (2002). Borjas (1999b, 2003, 2006) and Filler (1992) provide further evidence on the negative effects of immigration in the US. In a natural experiment setting of the Mariel boatlift which brought an influx 45,000 Cubans into Miami in 1980, Card (1990) finds that any effects of unexpected immigration were cancelled out by mobility response of natives and former immigrants. 
Considering the international evidence, Winkelmann and Zimmermann (1993) find only small negative effects of immigration on German employment. Hunt (1992) studied the impact of the Algerian repatriates on the French labour market after the Algerian independence and found detrimental but only weak wage and employment effects for the natives. Similarly, Carrington and de Lima (1996) find some evidence of negative effects on native wages of refugees from the lost colonies in Portugal. Angrist and Kugler (2003) report negative effects of immigration from former Yugoslavia on employment in Europe, especially in countries with more restrictive market institutions. Also Roy (1987) reports detrimental effects of immigration on native employment prospects in Canada. However, no negative effects of immigration on employment are reported by Pischke and Velling (1997) for Germany, Akbari and DeVoretz (1992) for Canadian natives, Dustmann, Fabbai, and Preston (2005) in the case of the UK, and Addison and Worwick (2002) for Australian natives. Roy (1997) reports no clear patterns of substitutability or complementarity between foreign- and Canadian-born labour. Friedberg (2001) finds no negative effects of Russian immigration on Israeli wages or employment. Zorlu and Hartog (2005) report little effects of immigration on native wages for the Netherlands, U.K and Norway. On the positive side, Chapman and Cobb-Clark (1999) and Parasnis, Fausten and Smyth (2006) find positive effects of immigration on the employment prospects of Australian natives. De New and Zimmermann (1994) support the complementarity hypothesis by finding negative effects of (largely unskilled) immigration on the wages of the German unskilled but positive wage effects on the wages of native high-skilled.

These interactions between immigrants and natives determine how immigrants fare across the earnings distribution in host societies. This issue has been addressed by a significant body of literature, including Borjas $(1990,1995)$ that focus on mean immigrant-native earnings gaps and Butcher and DiNardo (2002) and Chiswick, Le and Miller (2008) who investigate this gap at different deciles of earnings distribution. This literature generally reports significant earnings gaps whose magnitudes and determinants vary by gender, year and immigrant cohort as well as across the deciles of the earnings distribution. Employment gaps between immigrants and natives in the 
US labour market are documented by Chiswick, Cohen and Zach (1997) among others. Borjas (1986) reports higher self-employment rates among immigrants than natives. Gaps in various measures of labour market outcomes of immigrants and natives in other developed countries are reported by a number of studies, including Amuedo-Dorantes and de la Rica (2007) for Spain, Constant and Massey (2003) for Germany and Wheatly Price (1999) and Dustmann, Fabbri, Preston and Wadsworth (2003) for the UK.

One of the main determinants of this variation is the composition of immigrant inflows and the (self-)selection of immigrants. Another important aspect of immigrants' labour market success in the host society is the transferability of these skills to the host society. Dustmann, Frattini and Preston (2007) provide evidence that immigrants temporarily downgrade to less skilled occupations than they are qualified for due to incomplete transferability of their skills upon arrival. We further discuss the issues of selection and adaptation in Section 4.

The book edited by Zimmermann (2005b) contains 15 chapters for European countries and the US, Canada and New Zealand summarizing migration experiences since the Second World War. The conclusion obtained is that immigration is largely beneficial for the receiving countries. There can be phases of adjustment, but there is no overall evidence that natives' wages are strongly depressed or that unemployment is substantially increasing as a consequence of immigration. However, the labour market integration of immigrants has been slow, but steady, and their impact on the natives in total has not been very strong, but mostly beneficial. However, with globalization and the particular pressure on low-skilled workers and the rising demand for the high skilled, the observed patterns are changing. Most important, the economic position of the new immigrants has become weaker. A selective immigration policy seems to be even more important than before.

\section{A Stylized Model of the Labour Market Impacts of Immigration}

This section provides a simple theoretical setting to investigate the impacts of labour migration on the economy of the host country. Let us start with a very simple economy where labour is 
homogenous and capital is the only other production factor. Then, the standard textbook model using a competitive market framework is illustrated in Figure 3 with a fixed labour supply and a downward sloping labour demand curve. Denoting the quantity of labour $L$ and the wage level $w$, the equilibrium values are $w^{0}$ for the wage and $\bar{L}^{0}$ for employment. Additional employed workers (or immigrants) of size AB depress the wage level down to $w_{1}$. They migrate because they receive higher wages than at home (their income is the rectangle $\bar{L}^{0} \bar{L}^{1} \mathrm{AB}$ ), and are better off. Premigration labour loses the rectangle $\mathrm{ADw} w^{0} w^{1}$ to capital, which also takes the total welfare gain for the economy, ABD. However, wages may not be downward flexible, perhaps due to restrictions established by unions. ${ }^{12}$ Then immigration may cause unemployment at a maximum of $\mathrm{AB}$, given we started at full employment. Gains by immigrants and capital are thus associated with either lower wages, higher unemployment or both, depending on the degree of wage flexibility. This is often the picture behind the public debate about the impact of labour immigration.

Extending this simple equilibrium framework to the immigrants' countries of origin, the response there is symmetric: capital loses at first at the expense of labour. The countries of origin will further gain from parts of $\bar{L}^{0} \bar{L}^{1} \mathrm{AB}$ in the form of remittances. Migration, therefore, helps to reduce inequality across the world. We also learn that, if migrants stay, they become first immigrants and then even citizens, and this may change the calculation of inequality measures: At what stage do immigrants count in the evaluation of inequality, and how? Do the gains of capital justify redistribution efforts to compensate labour and to share the welfare gain ABD fairly?

As suggested above, there might be a union wage equal to $w^{0}$, imposing a threat of unemployment of level AB. However, in the face of competitive international markets with labour, capital, and technologies, unions might be under substantial pressure to reduce the union wage and allow the welfare gain to occur.

\footnotetext{
${ }^{12}$ See Schmidt, Stilz and Zimmermann (1994) for a theoretical treatment of this issue.
} 
A further and important issue is that the assumption of an invariant labour demand curve during the phase of immigration might be unfounded. This curve might shift due to migrants' additional demand for goods, the inflow of capital, or both. Assume that immigrants are economically identical to natives upon arrival, they are perfectly assimilated in the labour market and supply the same labour and bring the same amount of capital per person as the natives. A strict neoclassical world with a constant returns production function would then lead to point $\mathrm{C}$ with a shift in the labour demand function, full employment and additional production equal to the rectangle $w^{0} \mathrm{DC}$ all absorbed by the immigrants. Native labour and capital would both receive zero gains (or losses), since their parameters would remain unchanged. Immigrants, therefore, need to be "different" to have an economic impact.

As we have seen in Section 2, an important part of reality is that labour is heterogeneous, which brings the analysis to a different level. Immigration typically involves inflows of people who are on average more or less skilled than the native workers. As a result, it has important consequences for the distribution of skills in the economy. Furthermore, it affects the equilibria in the markets for skilled and unskilled labour and thus the distribution of income in the economy. To highlight the mechanisms that drive the effects of immigration on the host economy and to provide a powerful analytical instrument to study these mechanisms it is sufficient to concentrate on two types of labour only, the skilled $S$ and the unskilled $L{ }^{13}$ Therefore, we make a simplifying assumption that immigrant and native labour is homogenous within skill categories, which we relax in Section 4.

In line with standard production functions and empirical evidence, we can assume that skilled and unskilled workers are complements. ${ }^{14}$ We also assume for simplicity that the output price is constant. The key issues for the evaluation of the wage and employment effects of

\footnotetext{
${ }^{13}$ We use the terms skilled and educated interchangeably to describe workers' level of human capital. We, however, recognize the difference between the two terms; skills being the result of the learning process involving formal education as well as experience and practice, while education referring to the time spent in formal educational institutions. Thus, while in the theoretical part we prefer to use the broader term skills, in the empirical part we use the available measures on education.
} 
immigrant labour are then (i) whether the new workers are substitutes or complements to skilled or unskilled natives and (ii) what the equilibrium conditions are in the markets for skilled and unskilled labour in the host country. The first issue is about the share of skilled persons among the stock of immigrant workers, which is driven by immigration policies and self-selection. The answer to the second issue provides information whether both markets can be considered to be in a competitive equilibrium (as in the US) or the markets are in excess supply of low-skilled workers and in equilibrium or excess demand for the high skilled (as in Europe). Whichever the case, skilled immigration reduces the wages of skilled people and increases wages and employment of the unskilled. Hence, skilled immigration is "good" not only in an allocative sense (it provides an increase of general welfare as in the homogenous labour case), but it also improves equality in a heuristic sense. The "poor" fair better while the "rich" get less. For unskilled immigration we find the reverse situation.

Let us first illustrate the situation for unskilled immigration by use of Figure 4. While the labour market of the skilled is characterized by competitive conditions and equilibrium $\mathrm{A}^{0}$, we find a union wage $w_{l}^{0}$ higher than the equilibrium wage $w_{l}^{1}$ in the market for unskilled labour. This has generated unemployment at level $\bar{L}^{0}-L^{0}$ for the unskilled in the partial equilibrium $\mathrm{B}^{0}$. Then an inflow of unskilled migrant workers may just cause additional unemployment of size $\bar{L}^{1}-\bar{L}^{0}$, and nothing will happen in the market for skilled labour either. The economic position of the (poor) unskilled will deteriorate, however. Only if the union wage declines in the face of the additional competition from the immigrants, and the wage falls from $\mathrm{w}_{0}$ to $\mathrm{w}_{1}$, will this lead to more unskilled employment and through complementarity also to a higher demand for skilled workers. Consequently, wages of the high-skilled move up from $w_{h}^{0}$ to $w_{h}^{1}$ from equilibrium point $\mathrm{A}^{0}$ to $\mathrm{A}^{1}$. This effect is the stronger the more competitive is the market for unskilled labour. In sum, rising unemployment or falling wages for the poor (or both) and rising wages for the skilled workers mark

\footnotetext{
${ }^{14}$ See Hamermesh (1993).
} 
a reduction in the relative economic position of the poor, and provide an indication of increasing inequality. ${ }^{15}$

The evaluation of the immigration of skilled workers is even more obvious. The rise in the stock of skilled workers (see the shift in the supply curve from $\bar{S}^{0}$ to $\bar{S}^{1}$ in Figure 5a) moves the equilibrium point down from $C^{0}$ to $C^{1}$. The demand for unskilled workers increases due to complementarity (see the shift of the demand curve in Figure 5b) and under a competitive unskilled market, unskilled wages rise from $w_{l}^{2}$ to $w_{l}^{3}$ at the full employment level $\bar{L}$. Under a rigid union wage $\mathrm{w}_{0}$, the demand increase generates a higher level of employment of unskilled workers, whether $\left(D^{0}\right.$ to $\left.D^{1}\right)$ or not $\left(D^{0}\right.$ to $\left.D^{2}\right)$ the union wage decreases to $w_{l}^{1}$. Due to the complementarity of skilled and unskilled labour, the implied rise in unskilled employment ( $L^{0}$ to $L^{2}$ or $L^{1}$ ) causes an upward shift of the demand for skilled workers and partly counteracts the original wage decline, raising the skilled wage from $w_{h}^{1}$ to $w_{h}^{2}$. Hence, immigration of skilled labour is likely to cause a decline in skilled wages and a rise in unskilled employment, and in the case of a competitive equilibrium in the unskilled market, also a rise in low-skilled wages. This provides a strong rationale for the conjecture that skilled immigration reduces inequality.

\section{High-skilled Immigration Decreases Inequality}

We further investigate this issue in an analytical labour market model that relates inequality to skill composition of the labour force and then explicate its predictions for the inequality effects of migration. Consider an economy of size one with $L$ low-skilled and $S=1-L$ high-skilled workers earning wages $w_{l}$ and $w_{h}$, respectively. ${ }^{16}$ The graphical representation of the Gini coefficient as a measure of inequality in this economy is quite straightforward. Figure 6 plots the share of income accruing to the $\lambda$ poorest individuals in the economy, where we normalize income to unity,

\footnotetext{
${ }^{15}$ In practice it is often difficult to provide evidence of negative effects of unskilled immigration. This might have to do with the facts that immigrants provide different types of services and talents than even unskilled natives so that they are complements to both skilled and unskilled natives.
} 
$w_{l} L+w_{h}(1-L)=1$, and order individuals from the poorest to the most affluent. The Gini coefficient is the area between the line of perfect equality, the 45 degree line, and the Lorenz curve $z(\lambda)$, depicting the share of economy's income accruing to the $\lambda$ poorest individuals, divided by the area between the line of perfect equality and the line of perfect inequality. The line of perfect inequality attains zero for any $\lambda \in[0,1)$ and $z(1)=1$. Given the assumptions above, if the economy starts at point A the Gini coefficient is calculated as the size of the triangle $0 \mathrm{~A} 1$ divided by the triangular area below the line of perfect equality, 01. The slopes of the lines $0 \mathrm{~A}$ and $\mathrm{A} 1$ are $\theta /\left(\theta L^{1}+\left(1-L^{1}\right)\right)$ and $1 /\left(\theta L^{1}+\left(1-L^{1}\right)\right)$, respectively, where $\theta=w_{l} / w_{h}$.

How does the Gini coefficient change when wages or skill composition in the economy change? Consider an increase in the relative wage $\theta$, that might occur with an inflow of highly skilled migrants who depress the relative wages of the skilled natives. We still hold $L$ constant at $L^{1}$ in this analysis, assuming for the moment that our population of interest for measuring inequality are the incumbent natives only. Increasing $\theta$ increases the slope of the Lorenz curve for $\lambda \in\left[0, L^{1}\right]$ and decreases it for $\lambda \in\left[L^{2}, 1\right]$, such that the economy moves to point B. Clearly, the triangle 0B1 is smaller than 0A1 and Gini coefficient decreases, indicating a decrease in inequality. The effects of an increase in the share of low-skilled workers from $L^{1}$ to $L^{2}$, holding wages constant at the original level, has more intricate effects, as it is not obvious how the triangles 0A1 and 0C1 compare.

We tackle these issues analytically. We show in the Appendix that the Gini coefficient for a given $L$ is

$G(L)=\frac{(1-\theta) L(1-L)}{\theta L+(1-L)}$

Differentiating it with respect to the wage ratio, we obtain

${ }^{16}$ That is, we normalize the size of the labour force to unity and $L$ denotes also the share of lows-skilled workers. 


$$
d G(L) / d \theta=\frac{L(L-1)}{(1-L(1-\theta))^{2}},
$$

which is always negative for admissible values of $L$ and $\theta$, thus confirming the geometric analysis in Figure 6. Differentiating the Gini coefficient with respect to $L$ and assuming exogenous wages, we obtain

$$
\frac{d G(L)}{d L}=\frac{(1-\theta)(1-L(2-L(1-\theta)))}{(1-L(1-\theta))^{2}} .
$$

It follows that the sign of $d G(L) / d L$ is determined by the sign of $1-L(2-L(1-\theta))$, which is positive within the range $L \in[0,1]$ whenever $L<1 /(1+\sqrt{\theta})$, zero for $L=1 /(1+\sqrt{\theta})$, and negative otherwise. $^{17}$ Thus, in Figure 6 the triangle 0C1 is larger than 0A1 if $L<1 /(1+\sqrt{\theta})$ holds and smaller if it does not. Noting that $0.5<1 /(1+\sqrt{\theta})<1$ for any $\theta \in(0,1), G(L)$ attains a maximum for some $L \in(0.5,1)$ and thus $G(L)$ is increasing on the larger part of the admissible range of $L$. Figure 7 shows how $G(L)$ might look like as a function of the share of skilled labour in the case of exogenous wages, where $L^{0}$ denotes the level of $L=1 /(1+\sqrt{\theta})$.

Figure 8 illustrates the effects of immigration on the economy for an exogenously given wage ratio, as might be the case in some Western European countries with strong union regulation. For example, an inflow of immigrants who are on average more skilled than the natives lowers $L$ in the economy. If the share of low skill workers in the economy is low and/or the wage gap is large such that $L<1 /(1+\sqrt{\theta})$, this decrease in $L$ decreases inequality measured by the Gini coefficient. This is the case in the upper right triangle in Figure 8. The inflow of low-skilled immigrants that increases $L$ has corresponding converse effects. ${ }^{18}$

\footnotetext{
${ }^{17}$ See the Appendix for the derivation of these properties.

${ }^{18}$ The effects on the source countries are the mirror image of those on the destination countries.
} 
Let us now investigate the effects of immigration on inequality in a more realistic setup, relaxing the assumption of exogenous wages. We let $\theta=\theta(L)$ and, for the sake of simplicity, consider a specific case with the Constant Elasticity of Substitution (CES) production function $C=\left(L^{1-\rho}+(\alpha S)^{1-\rho}\right)^{\frac{1}{1-\rho}}$, where $\rho=1 / \varepsilon$ and $\varepsilon>0$ is the (finite) elasticity of substitution of highand low-skilled labour in a competitive industry and $\alpha>1$ is the efficiency shift factor of skilled relative to unskilled labour. Under these assumptions $\theta=(L /(\alpha(1-L)))^{-\rho}$ and the earnings of an unskilled relative to a skilled worker are $\theta / \alpha$. We first consider the natural case where the earnings of high-skilled workers are higher than those of low-skilled ones, $\theta / \alpha<1$. In the Appendix we show that the Gini coefficient in the case is

$G(L)=\frac{L(1-L)\left(\alpha-(\alpha(1-L))^{\rho} / L^{\rho}\right)}{\alpha-\alpha L+(\alpha(1-L))^{\rho} / L^{\rho-1}}$

and that there is a nondegenerate range $L^{1} L^{2}$ within the interval $[0,1]$ where $G(L)$ is increasing in $L$. In fact, whenever $\varepsilon \in(0,1], d G(L) / d L>0$ for any $L \in(0,1)$. For $\varepsilon>1, G(L)$ is increasing within and decreasing outside of $L^{1} L^{2}$, that is, for very low and very high values of $L$. It turns out that the range $L^{1} L^{2}$ tends to be quite large. ${ }^{19}$ Parametric values determine which $L \in(0,1)$ are admissible with respect to the condition $\theta / \alpha<1$ and which are not. We denote $L^{*}$ the value of $L$ at which $\theta / \alpha=1$. One can show that $L^{*}=\alpha^{1-1 / \rho} /\left(1+\alpha^{1-1 / \rho}\right), L^{1}<L^{*}<L^{2}$, and $\theta / \alpha<1$ for any $L \in\left(L^{*}, 1\right)$ and $\theta / \alpha>1$ for any $L \in\left(0, L^{*}\right) \cdot{ }^{20}$ It turns out that for the values of $L \in\left(0, L^{*}\right)$ the Gini coefficient equals $-G(L)$. How the Gini coefficient might look like as a function of the share of

\footnotetext{
${ }^{19}$ For example, if the substitutability of skilled and unskilled labour is about 2.5, as estimated by Chiswick (1978C), and high skilled labour is twice as productive as its low skilled counterpart, the corresponding values are $L^{1}=0.07$ and $L^{2}=0.83$.
} 
skilled labour, $1-L$, in case of flexible wages is shown in Figure $7 .{ }^{21}$ Note that for OECD economies with a large share of skilled labour the relevant segment of $G(L)$ is decreasing in $1-L$ for the most part and may pick up for $L \in\left(0, L^{*}\right)$, where, counterfactually, the low-skilled earn more than the high-skilled.

This result enables us to consider the effects of changes in $L$ that occur when immigrants of different skill composition (vis-à-vis the natives) enter (leave) the economy under the conditions of flexible wages. In Figure 9 the arrows indicate the effects of immigration on inequality in the economy, for various combinations of shares of skilled and unskilled labour among the natives and immigrants. For example, in the upper central trapezoid for $L \in\left(L^{*}, L^{2}\right)$ an inflow of immigrants who are on average more skilled than the natives decreases inequality in the economy. ${ }^{22}$

To summarize, theory predicts that skilled immigration decreases inequality in advanced economies such as the OECD countries where skilled labour is abundant. Accounting for the endogeneity of wages confirms this result, predicting that inequality is decreasing with skilled immigration for moderate to high values and may be increasing for very high values of the share of skilled labour, 1-L. We examine this theoretical result empirically in the next section.

\section{The Gini Coefficient and the Educated Labour Force}

As discussed in the previous section, theory predicts a negative relationship between inequality and the share of skilled labour in the labour force, which is itself a function of immigrants' skills, for advanced economies where skilled labour is abundant. We, therefore, analyze here the empirical relationship between inequality and educational attainment levels in the labour force. ${ }^{23}$ We combine

\footnotetext{
${ }^{20}$ See Zimmermann and Kahanec (2008a). Note, that if $\varepsilon>1(\varepsilon \in(0,1)$ ), it must be that $L<0.5$ ( $L>0.5)$ for $\theta / \alpha<1$ to hold. $L^{*}=0.26$ under the assumptions of the previous footnote.

${ }^{21}$ In Figure 7 we consider the possibility that $\varepsilon>1$. If $\varepsilon \in(0,1], G(L)$ is decreasing over the whole range and the Gini coefficient thus exhibits a V-shaped curve on $L \in(0,1)$.

${ }^{22}$ Note that we consider the case $\varepsilon>1$ in the figure.

${ }^{23}$ As mentioned earlier, education measures a certain type of skills.
} 
data on education, labour force characteristics and other national indicators from the OECD Statistical Compendium 2007 with the Gini measures reported in the World Income Inequality Database (WIID 2007) version 2.0b compiled by the WIDER institute at the United Nations University and published in May 2007. The OECD Statistical Compendium provides historical statistics on a wide range of economic variables, such as labour force characteristics, national accounts, and education, mainly for developed countries that are members of OECD.

The WIID 2007 dataset reports Gini coefficients for a large number of countries covering many years of collection and estimation of this inequality indicator. In those cases where WIID 2007 reports multiple Gini coefficients per year and country, we prefer those of the highest quality if based on gross rather than net takings and earnings rather than broader measures of income to quantify those components of economic inequality that stem from the labour market as precisely as possible. $^{24}$ The combined dataset covers 29 OECD member states and provides 158 (154) observations with non-missing information on the Gini coefficient the shares of the labour force with at least upper secondary (post-secondary) education.

Figures 10 and 11 plot the Gini coefficient against the shares of educated labour at work measured by the abovementioned variables. We observe a U-shaped relationship that is downward sloping for the most part of the observed data. To investigate the properties of these relationships more precisely, we compute the predicted values of a locally smoothed regression of the Gini coefficient on the measures of educational attainment in the labour force. The plots in Figures 12 and 13 confirm the U-shaped character of the observed relationships. In fact, these relationships are not too different from simple quadratic fits. These figures confirm that both relationships are negative for the most part. Indeed, this relationship is negative for about $80 \%$ of the observations in

\footnotetext{
${ }^{24}$ It needs to be acknowledged that whether earnings inequality is measured at the individual or household level is a non-trivial issue in the context of measuring the relationship between inequality and immigration. In particular, immigrants often have larger households and different family structures than natives. As a result, measures of inequality based on individual and household earnings may give different pictures of inequality. The analysis of this complex relationship is beyond the scope of this chapter, however. Nevertheless, we control for the level (individual vs. household) at which the Gini coefficient was measured in our empirical analysis.
} 
case of post secondary or higher education. The corresponding percentage for upper secondary or higher education is about $60 \%$.

However, there are factors other than the distribution of educational levels in the labour market that may influence this relationship. For example, Katz and Murphy (1992) argue that increased demand for skilled workers and females as well as changes in the allocation of labour between industries contributed to increasing inequality in the US in recent years. Gustafsson and Johansson (1999) find that the share of industry in employment, per capita gross domestic product, international trade, the relative size of the public expenditures, as well as the demographic structure of the population affect inequality measured by the Gini coefficient across countries and years. Topel (1994) provides evidence that technological and economic development determine economic inequality.

To examine whether the observed decreasing and U-shaped relationship is robust with respect to the possible covariates mentioned in the literature, we tested its stability using the OLS model and the same dataset and variables as above. As potential covariates we considered aggregate and female labour force participation rates, aggregate and female unemployment rates, share of the population between 15 and 64 years of age, labour force in the agricultural sector, share of the government in the economy, gross domestic product and inflation rate, as well as a number of controls for the character and quality of the data on Gini coefficient, year, and country. A regression analysis by Kahanec and Zimmermann (2008) confirms that the observed decreasing and U-shaped relationship is robust and significant over a number of model specifications, including models with weighing by data quality and country size, clustering, and random and fixed country effects. The estimated coefficients predict the minimum of the U-shaped relationship between the share of skilled labour and the Gini coefficient to lie at about $75 \%$ of the labour force with upper secondary or higher education and $65 \%$ of the labour force with post secondary or higher education. In our sample these numbers imply a downward sloping relationship between the share of skilled labour 
and inequality for about $62 \%$ and $83 \%$ of the observations for the two applied measures of skilled labour, respectively.

\section{Immigrant Absorption, Selection and Ethnicity}

Demand, Supply and Policy Measures

There are many channels through which immigration affects the host economy. Immigration brings in new people with diverse characteristics and economic aptitudes, it affects the economic prospects of the native population and it impinges on the decisions of important economic and policy actors. The labour market status of immigrants is a principal measure of immigrants' success in the destination economy. After proper adaptation to the host country, immigrants can fully utilize their skills, possibly turning from low into high-skilled labour. As shown in the previous section, the skill level of immigrants affects inequality. Therefore, the degree of immigrants' labour market assimilation are in turn an important determinant of economic inequality in the host society.

Immigrant selection is one approach to react to concerns about the absorption process of immigration based on clear admission criteria and immigration policies (Zimmermann, 2005a, 2005b; Constant and Zimmermann, 2005) for an evaluation of immigration policies across countries.) Constant and Zimmermann (2005) aim to understand the role of the legal status of the migrant at the time of entry in the host country (work permit, refugee, and kinship) on work participation and earnings using individual survey data for Denmark and Germany. Their research suggests that non-economic migrants are less qualified for the labour market and exhibit lower earnings even having controlled for skill-level. Arriving through family reunion or as asylum seekers or refugees affects paid-employment earnings negatively in both Germany and Denmark. However, while the effect is about the same size for both groups in Denmark, the refugee/asylum status is more harmful in Germany than the family reunion status. Individuals arriving with a work status in Germany are more likely to earn less when changing to self-employment than when arriving through another channel. These estimates suggest that there are long-lasting effects of the 
legal status at entry in the country on the earnings potential of immigrants. Hence, a selective immigration policy might be helpful in ensuring the attraction of more talented individuals.

There is some confusion about how to study immigrant absorption into the host country's society and economy. Economists typically have discussed "assimilation" as the process where (i) immigrant earnings each year comes closer to the earnings of an equivalent native (Chiswick, 1978) or (ii) among two observationally equivalent immigrants the one with the longer presence in the host country earns more (LaLonde and Topel, 1992, p. 75). As Borjas (1999a, p. 1721) has pointed out, it is important to stress in the analysis what the relevant reference group is. In our context it is important to deal with the question how immigrants become economically like natives. They might earn less upon arrival, but converge with time spend in the country after adapting to the host country labour market. This economic absorption, however, does not have to be complemented by cultural absorption, that is ethnic identity of the immigrant might evolve separately and exhibit an independent effect on economic performance. We, therefore, distinguish here between economic assimilation and cultural or ethnic assimilation. ${ }^{25}$

\section{Economic Assimilation}

The pioneering work of Chiswick (1978) investigates the economic assimilation of immigrants defined as earnings parity between immigrants and natives and their age earning profiles in a cross sectional setting. The typical pattern observed in cross-sectional data features three distinct attributes. First, upon arrival, immigrants' earnings are significantly below those of natives, holding observable skills constant. This finding is typically ascribed to immigrants' lack of certain unobservable skills, non-transferability of their skills, and their lack of information specific to the host economy, including language, educational qualifications, and general information about the

\footnotetext{
${ }^{25}$ According to Webster's Collegiate Dictionary assimilation is "the process whereby individuals or groups of differing ethnic heritage are absorbed into the dominant culture of a society."
} 
host labour market. Second, with experience in the host economy, however, immigrants acquire the missing skills and information and catch up with the natives.

Finally, the evidence in the US is that after a certain period of converging to the native level of earnings, immigrants seem to earn more than natives. The standard human capital model does not offer simple explanations of this finding. The typical explanation offered by economists is selection, the innate (unobservable) ability of immigrants and their drive and determination to succeed in the new country. Since the decision to migrate involves weighing the costs and benefits of migration, people with stronger economic prospects in the destination economy are more likely to migrate and, therefore, after a period of adjustment on average outperform the representative native population.

The cross sectional analysis could thus explain why immigrants who migrated in the more distant past earn more than their more recent counterparts. However, the cross sectional data may hide certain cohort effects as argued by Borjas (1985). In particular, more recent immigrants can be inherently different to those who arrived some years ago. If these more recent arrivals are unobservably less skilled than the older cohorts, cross sectional data cannot distinguish these cohort effects from the assimilation hypothesis described above. Cohort effects may be driven by changes in the immigration policy of the host country or by institutional and political changes in the source countries. For example, refugees from the Soviet Bloc to Germany were typically highly skilled professionals. After the fall of the Berlin Wall, however, migration barriers were lessened and a much more varied sample of people decided to migrate to the West.

The empirical evidence on the cohort effects suggests that these effects may be quite large. ${ }^{26}$ Borjas (1995) provides evidence that the educational attainment of immigrant cohorts in the US declined by 1.8 years of schooling between 1960 and 1990 and that the age-earnings profiles of the 1950-59 cohort are higher than those of the 1970-79 cohort throughout the life cycle. In particular, while the earlier cohort's age-earnings profiles are above those of the natives, the more recent

\footnotetext{
${ }^{26}$ Borjas (1994) surveys the early literature.
} 
immigrants' profiles are inferior to the natives'. These cohort effects suggest that more recent arrivals will hardly assimilate and never fully catch up with the natives.

Figure 14 plots the hypothetical age-earnings profiles of two immigrant cohorts and the natives. According to the assimilation hypothesis, the early cohort of immigrants quickly catches up with the natives surpassing them after some adjustment time. On the other hand, the more recent immigrant cohort has poor labour market characteristics that drive their age-earnings profiles below those of the natives and the earlier immigrant cohort throughout the lifecycle and no assimilation occurs.

Immigrant assimilation has important consequences for inequality in the host economy. Under the assimilation hypothesis, immigration affects earnings inequality in the host economy in two ways. First, fresh immigrants earn below average wages and thus increase the number of lowpaid workers. After a certain assimilation period, however, positively selected immigrants earn more than the average native and thus increase the number of high-paid workers. Given our earlier theoretical results, if immigrants first behave as low-skilled and then, after an adjustment period, as high-skilled, immigration eventually lowers earnings inequality. The exact magnitude of this effect is importantly determined by the speed of the assimilation process. The cohort effect hypothesis, on the other hand, predicts that immigration invariably contributes to the number of low-pay workers and that these effects are invariant over time and immigrants' life cycle.

The literature has identified a single most important factor driving the declining relative skills across immigrant waves: the changing composition of immigrants as concerns their country of origin. ${ }^{27}$ For the US, Borjas (1990) reports a significant shift of the composition of new arrivals, Latin American and Asian immigrants replacing those of European origin. The relatively facile transferability of human capital between developed countries as compared to the transfer from less developed to developed countries and the abovementioned increase in the share of immigrants from

\footnotetext{
${ }^{27}$ Chiswick (1999) discusses the theoretical approaches to self-selection, noting that especially migrants whose main reason to migrate are economic opportunities tend to be favourably self-selected.
} 
less developed countries explains why more recent immigrants have lower skills. The higher opportunity costs of migration in high-GDP countries leading to selection of only immigrants with the best economic prospects further elucidates why immigrants from less developed countries are less skilled.

This selection argument can be extended to different skill groups within and between source countries. ${ }^{28}$ The character of the earnings distribution in the source country affects the migration incentives of high and low skill workers differently. In a country that has a relatively flat earnings distribution the opportunity costs of migration are higher for the low skilled workers who enjoy wealth redistribution in their favour. On the other hand, in a country with a relatively steep income distribution it is the high skilled who enjoy high returns to skills and have high opportunity costs of migration (Borjas, 1985). As a result, we can expect that high-skill (low-skill) migrants will move from countries that have a flatter (steeper) income distribution than the destination country. The logic of this argument can easily be explained using the Roy model. ${ }^{29}$ Consider people in the source country making their migration decision based on the expected wage in the source and destination countries. Assume that earnings are determined solely by individual skills such that

$$
\begin{aligned}
& w_{s}=\alpha_{s}+\gamma_{s} s \\
& w_{d}=\alpha_{d}+\gamma_{d} s
\end{aligned}
$$

where $w$ denotes wages, $\alpha$ is the shift factor and $\gamma$ denotes the returns to skills $s$. Subscripts $s$ and $d$ denote the source and destination country, respectively. The migration decision is illustrated in Figure 15. Panel a) depicts skill-earnings profiles (1) and (2) in the situation where the source country is more egalitarian than the destination country. After the break even point $b_{p}$ migration becomes an attractive option and immigrants are positively selected on skills. In panel b), on the other hand, it is the destination country that is relatively more egalitarian and $b_{p}$ marks the break even point of skill-driven negative migrant selection. According to this model, it is not the average 
income level in the source and destination country that drive skill-based selection of migrants. Rather, it is the relative distribution of income. ${ }^{30}$

The Roy model has important implications for income distribution in the source and destination countries as a function of immigrants' self-selection. It predicts that the more (less) egalitarian the destination country is, the higher the likelihood that it attracts low (high) skill immigrants. In effect, egalitarian (non-egalitarian) destination countries are prone to earnings inequality with a concentration of immigrants at the lower (upper) tail of the earnings distribution.

On the other hand, egalitarian (non-egalitarian) source countries are likely to experience an uneven distribution of earnings with a thin upper (lower) tail.

These distributional aspects highlight the role of immigration policy for earnings inequality between and within immigrant and native groups in the host society. Focusing on Europe and Germany and Denmark in particular, Constant and Zimmermann (2005) provide evidence that these countries could benefit from more pro-active policies aiming at recruitment and integration of immigrants with strong economic prospects. An example of such policy is selection of qualified immigrants using observable and measurable criteria. Such policies would lower the shares of immigrants with inferior economic aptitude in the host economy. Depending on the selection criteria, such polices have a solid potential to reduce income inequality and immigrant poverty in the destination countries.

\section{Ethnicity and Ethnic Identity}

Ethnic identity, much like personality and other individual characteristics, are supposed to substantially influence labour market outcomes and thus inequality. Ethnic identity is whatever makes individuals the same or different in comparison to other ethnic groups. It may also encompass a network of strong beliefs, values, and what people hold dear. Ethnic identity surfaces

\footnotetext{
${ }^{28}$ Another extension would be the self-selection of migrants who decide to return to their home countries, or to third countries. See e.g. Borjas (1989), Constant and Massey (2003), Dustmann (2003), and Galor and Stark (1991).

${ }^{29}$ Roy (1951) and Borjas (1987b).
} 
and becomes a strong part of the migrants' persona when they arrive in a host country that is dominated by a different ethnicity or culture.

There is a growing and related literature studying the evolution of culture and ethnic identity and its role for economic outcomes. Ottaviano and Peri (2006) and Guiso, Sapienza, and Zingales (2006) deal with the mixed impact of culture. Kahanec (2007) investigates how the interaction of social relationships and ethnicity drive ethnic competition and specialization in the labour market. Theories of ethnic identity (Kuran, 1998; Fearon and Laitin, 2000; Darity, Mason, and Stewart, 2006; Austen-Smith and Fryer, 2005; Chiswick, 2006; Battu, Mwale and Zenou, 2007) and empirical studies (Mason, 2004; Constant, Gataullina, and Zimmermann, 2006a and 2006b; Bisin, Patacchini, Verdier, and Zenou, forthcoming; Nekby and Rödin, 2007) provide a better understanding of societal and economic behaviour.

We follow Constant, Gataullina, and Zimmermann (2006a) to define ethnic identity as the balance between the commitment to or self-identification with the culture and society of the origin and host countries. We conjecture that a migrant who arrives in the host country moves along a plane formed by two axes representing commitment to the home and host countries. On the horizontal axis we measure commitment to and self-identification with the country of origin, and on the vertical axis we measure commitment to and self-identification with the host country.

Confronted with both cultures, which combination of commitments do migrants choose to uphold? The two-dimensional ethnosizer, a measure of the intensity of a person's ethnic identity, deals with this question and conceptualizes the position of migrants in the positive orthant of commitment combinations. As illustrated in Figure 16, the ethnosizer contains four measures or regimes of ethnic identity differentiated by the strength of cultural and social commitments. Assimilation (A) is a strong identification with the host culture and society, coupled with a firm conformity to the norms, values, and codes of conduct, and a weak identification with the ancestry; Integration (I) is achieved when an individual combines, incorporates, and exhibits both strong

\footnotetext{
${ }^{30}$ See Chiswick (1999) for a more general treatment of self-selection. Chiquiar and Hanson (2005) provide evidence
} 
dedication to the origin and commitment and conformity to the host society; Marginalization (M) is a weak dedication to or strong detachment from either the dominant culture or the culture of origin; and, Separation (S) is an exclusive commitment to the culture of origin even after years of emigration, paired with weak involvement in the host culture and country realities. Starting at point $(1,0)$, a migrant can undergo a more complicated journey through the various states, leaving separation towards integration, assimilation or marginalization, or remaining separated.

The ethnosizer is constructed by using individual data with information on the following elements: language, culture, societal interaction, history of migration, and ethnic self-identification (Constant, Gataullina, and Zimmermann, 2006a). We briefly summarize some recent findings about the effects of ethnic identity on economic behaviour. ${ }^{31}$ Constant, Gataullina, and Zimmermann (2006b) deal with the probability to work, Zimmermann (2007) with earnings, and Constant, Roberts and Zimmermann (2007) with homeownership. All three papers use the German Socioeconomic Panel (GSOEP) and employ Probit (work probability, homeownership) and Tobit models (earnings). The two-dimensional ethnosizer is added to standard regressions to examine the particular contribution of ethnic identity. Consistently, it is found that ethnicity matters significantly for economic performance and that the findings are very robust with respect to the concrete model specification. To put it differently: The inclusion of the ethnosizer does not change the parameter estimates of the standard variables in any relevant way. Nevertheless, the parameter estimates of the ethnicity effects have a strong impact on economic behaviour. Assimilation and integration have a positive effect on economic performance, while separation and marginalization do not.

As discussed above, the economic literature on assimilation considers economic assimilation, which suggests that immigrants may finally converge to the economic behaviour and performance of natives. The issue is the speed of this process. The ethnicity literature considers ethnic identity as cultural capital that may emerge and develop, but likely persists over time and

\footnotetext{
inconsistent with the negative selection hypothesis hypothesized by Borjas (1987b).

${ }^{31}$ Constant and Zimmermann (2008) provide an overview of this research and present evidence that the measures of ethnic identity (the ethnosizer) are exogenous.
} 
exhibits comparative advantages and disadvantages for the economic process. This approach may help to explain why different ethnic groups can be observed to exhibit very different positions in the distribution of income and why some stay at the lower tail of income distribution while others move up and close the gap vis-à-vis the natives.

\section{Conclusions and Further Research}

The analysis in this chapter suggests that skilled labour immigration has a large potential to reduce inequality in the receiving countries. An important channel is the rise in relative wages of the unskilled with respect to the wages of the skilled. Unskilled immigration seems to generally increase inequality, only under specific circumstances it may decrease it. Such an instance is, if migrant adaptation overcomes downgrading, immigrants may turn from low- to high-skilled workers.

But the relationship between inequality and the presence of immigrants in the economy is not trivial. Complementarities between skilled and unskilled (immigrant) labour and ethnic capital, or the role of skilled and unskilled immigrants in satisfying the taste for variety in the host economy may affect inequality in complex ways. One has to be aware also of the different institutional and social histories of immigration and inequality across countries. Immigrants differ across countries, not only in terms of ethnic origin but also in terms of educational attainment, ethnic identity and societal and economic aspirations.

The flow of labour migration depends on incentives, but also on inequality in the sending and receiving countries. The relative inequality in the source and destination countries affects the prospects of immigrants with different skill levels differently, and thus feeds into the selection of

immigrants across destination countries. Many immigrants do not remain migrants forever. Some of them assimilate, some integrate, some return, and some remain trapped in different degrees of social and labour market exclusion. The dynamics of the allocation of immigrants across these states importantly affects their labour market position as well as that of the natives and thus inequality. 
With the rising excess demand for skilled labour worldwide, and the positive consequences of labour migration for allocative and distributional purposes, there is a large potential for an international policy regime of unrestricted temporary and circular skilled labour migration. Highlyskilled workers could obtain a global green card to work in their country of choice depending on the availability of a work contract. This could contribute to global welfare and more equality, since such a temporary and circular migration regime makes the best use of scarce brains and ensures that both sending and receiving regions receive their share of the gains of migration.

This has to be made possible by further research in various areas: Given the complexity of the effects and causes that the relationship between migration and inequality involves, in the next 10 years we should concentrate our research on the causal effects of migration on inequality in the host and sending countries as well as on world inequality. We understand already many parts of this link, but the big picture is unclear due to the lack of data. Some of the specific issues that need further attention include the (i) effects on sending countries generated by brain drain, the (ii) intertwined effects between immigration, immigration policy, attitudes towards immigrants, and immigrants labour market outcomes, and (iii) the interactions between immigrant assimilation, ethnic capital, and immigrants' labour market outcomes. 


\section{References}

Adams, R. (1989). 'Workers Remittances and Inequality in Rural Egypt'. Economic Development and Cultural Change, 38: 45-71.

Adams, R. (1992). 'The Impact of Migration and Remittances on Inequality in Rural Pakistan'. Pakistan Development Review, 31: 1189-1203.

Addison, T. and C. Worswick (2002). 'The Impact of Immigration on the Earnings of Natives: Evidence from Australian Micro Data'. The Economic Record, 78: 68-78.

Akbari, A. and D. DeVoretz (1992). 'The Substitutability of Foreign-Born Labour in Canadian Production: Circa 1980'. Canadian Journal of Economics, 25: 604-614.

Amuedo-Dorantes, C. and S. de la Rica (2007). 'Labour Market Assimilation of Recent Immigrants in Spain'. British Journal of Industrial Relations. 45: 257-284.

Angrist, J. D. and Adriana D. Kugler (2003). 'Protective or Counter-Protective? Labour Market Institutions and the Effects of Immigration on EU Natives'. The Economic Journal, 113: F302-F331.

Austen-Smith, David, and Roland G. Fryer Jr. (2005). 'An Economic Analysis of 'Acting White'. Quarterly Journal of Economics, 120: 551-583.

Barham, B. and S. Boucher (1998). 'Migration, Remittances and Inequality: Estimating the Net Effects of Migration on Income Distribution'. Journal of Development Economics, 55: 307331.

Bauer, T. and K. F. Zimmermann (1997). 'Integrating the East: The Labour Market Effects of Immigration', in S. W. Black (ed.), Europe's Economy Looks East-Implications for the EU and Germany. Cambridge: Cambridge University Press, 1997, 269-306.

Battu, H., M. Mwale and Y. Zenou (2007). 'Oppositional Identities and the Labour Market'. Journal of Population Economics, 20: 643-667.

Bisin, A., E. Patacchini, T. Verdier and Y. Zenou (forthcoming). 'Are Muslim Immigrants Different in Terms of Cultural Integration?'. Journal of the European Economic Association.

Borjas, G. J. (1983). 'The Substitutability of Black, Hispanic, and White Labour'. Economic Inquiry, 21: 93-106.

Borjas, G. J. (1985). 'Assimilation, Changes in Cohort Quality, and the Earnings of Immigrants', Journal of Labour Economics, 3: 463-489.

Borjas, G. J. (1986). 'The Self-Employment Experience of Immigrants'. The Journal of Human Resources, 21: 485-506.

Borjas, G. J. (1987a). 'Immigrants, Minorities, and Labour Market Competition'. Industrial and Labour Relations Review, 40: 382-392.

Borjas, G. J. (1987b). 'Self-Selection and the Earnings of Immigrants'. American Economic Review. 77:531-553. 
Borjas, G. (1989). 'Immigrant and Emigrant Earnings: A Longitudinal Study'. Economic Inquiry. 27: 21-37.

Borjas, G.J. (1990). Friends or Strangers: The Impact of Immigrants on the US Economy. New York: Basic Books.

Borjas, G.J. (1994). 'The Economics of Immigration'. Journal of Economic Literature, 32: 16671717.

Borjas, G.J. (1995). 'Assimilation and Changes in Cohort Quality Revisited: What Happened to Immigrant Earnings During the 1980s? ' Journal of Labour Economics, 13: 201-245.

Borjas, G. J. (1999a). 'Economic Analysis of Immigration', in: Ashenfelter, O. C. and D. Card (1999). Handbook of Labour Economics (Volume 3A). Amsterdam: Elsevier, 1999, 16971760 .

Borjas, G. J. (1999b). Heaven's Door: Immigration Policy and the American Economy, Princeton, New Jersey: Princeton University Press.

Borjas, G. J. (2003). 'The Labour Demand Curve is Downward Sloping: Reexamining the Impact of Immigration on the Labour Market'. Quarterly Journal of Economics, 118: 1335-1374.

Borjas, G. J. (2006). Immigration in the High-Skill Labour Markets: The Impact of Foreign Students on the Earnings of Doctorates, National Bureau of Economic Research, Working Paper, No. 12085.

Borjas, G. J., R. B. Freeman, and L. F. Katz (1997). 'How Much Do Immigration and Trade affect Labour Market Outcomes? ' Brookings Paper of Economic Activity, 1: 1-67.

Butcher, K. F. and J. DiNardo (2002). 'The Immigrant and Native-Born Wage Distributions: Evidence from United States Censuses'. Industrial and Labor Relations Review, 56: 97-121.

Card, D. (1990). 'Impact of the Mariel Boatlift on the Miami Labour Market'. Industrial and Labour Relations Review, 43: 245-257.

Card, D. (2001). 'Immigrant Inflows, Native Outflows and the Local Labour Market Impacts of Higher Immigration'. Journal of Labour Economics, 19: 22-64.

Carrington, W. J. and P. J. F. de Lima (1996). 'The Impact of 1970s Repatriates from Africa on the Portuguese Labor Market'. Industrial and Labor Relations Review, 49: 330-347.

Chapman, B. and D. Cobb-Clark (1999). 'A Comparative Static Model of the Relationship between Immigration and the Short-Run Job Prospects of Unemployed Residents'. Economic Record, 75: 358-68.

Chiquiar, D. and G. H. Hanson (2005). 'International Migration, Self-Selection, and the Distribution of Wages: Evidence from Mexico and the United States'. Journal of Political Economy. 113: 239-281.

Chiswick, B. R. (1978). 'The Effect of Americanization on the Earnings of Foreign-Born Men'. Journal of Political Economy, 86: 897-921. 
Chiswick, B. R. (1980). An Analysis of the Economic Progress and Impact of Immigrants, Employment and Training Administration. U.S. Department of Labour. National Technical Information Service, PB80-200454.

Chiswick, B. R. (1998). 'The Economic Consequences of Immigration: Application to the United States and Japan', in: Myron Weiner and Tadashi Hanami (eds.), Temporary Workers or Future Citizens? Japanese and U.S. Migration Policies, New York: New York University Press, 1998, 177-208.

Chiswick, B. R. (1999). 'Are Immigrants Favorably Self-Selected?' American Economic Review, 89: 181-185.

Chiswick, B. R. and T. J. Hatton, (2003). 'International Migration and the Integration of Labour Markets'. in: M. Bordo, A. Taylor and J. Williamson (eds.), Globalization in Historical Perspective, NBER Conference Report, 65-119.

Chiswick, B. R. and P. W. Miller (2002). 'Immigrant Earnings: Language Skills, Linguistic Concentrations and the Business Cycle'. Journal of Population Economics, 15: 31-57.

Chiswick, B. R., Y. Cohen and T. Zach (1997). 'The Labor Market Status of Immigrants: Effects of the Unemployment Rate at Arrival and Duration of Residence'. Industrial and Labor Relations Review, 50: 289-303.

Chiswick, B. R., A. T. Le and P. W. Miller (2008). 'How Immigrants Fare Across the Earnings Distribution: International Analysis'. Industrial and Labor Relations Review, 61: 352-373.

Chiswick, C. U. (1978C). 'The Growth of Professional Occupations in U.S. Manufacturing, 190073'. in: I . Sirageldin (ed.), Research in Human Capital and Development, Greenwich, Conn.: JAI Press, 191-217.

Chiswick, C. U. (2006). The Economic Determinants of Ethnic Assimilation. IZA Discussion Paper No. 2212.

Chiswick, C. U., B. R. Chiswick and G. Karras (1992). 'The Impact of Immigrants on the Macroeconomy'. Carnegie-Rochester Conference Series on Public Policy, 37: 279-316.

Constant, A. and D. S. Massey (2003). 'Self-Selection, Earnings, and Out-Migration: A Longitudinal Study of Immigrants to Germany'. Journal of Population Economics. 16: 631653.

Constant, A., and K. F. Zimmermann (2005). 'Immigrant Performance and Selective Immigration Policy: A European Perspective'. National Institute Economic Review, 194: 94-105

Constant, A., and K. F. Zimmermann (2008). 'Measuring Ethnic Identity and Its Impact on Economic Behavior'. Journal of the European Economic Association, forthcoming.

Constant, A., L. Gataullina, and K. F. Zimmermann (2006a). Ethnosizing Immigrants. IZA Discussion Paper No. 2040. Journal of Economic Behavor and Organization, forthcoming.

Constant, A., L. Gataullina, and K. F. Zimmermann (2006b). Gender, Ethnic Identity and Work. IZA Discussion Paper No. 2420. 
Constant, A., R. Roberts, and K. F. Zimmermann (2007). Ethnic Identity and Immigrant Homeownership. IZA Discussion Paper No. 3050.

Darity, W. A., P. L. Mason, and J. B. Stewart (2006). 'The Economics of Identity: The Origin and Persistence of Racial Identity Norms'. Journal of Economic Behavior and Organization, 60: 283-305.

De New J. P. and K. F. Zimmermann (1994). 'Native Wage Impacts of Foreign Labour: a Random Effects Panel Analysis'. Journal of Population Economics, 7: 177-192.

Dustmann, C. (2003). 'Return Migration, Wage Differentials, and the Optimal Migration Duration'. European Economic Review. 47: 353-369.

Dustmann, C., F. Fabbai and I. Preston (2005). 'The Impact of Immigration on the UK Labour market'. The Economic Journal, 115: F324-F341.

Dustmann, C., F. Fabbri, I. Preston and J. Wadsworth (2003). Labour Market Performance of Immigrants in the UK Labour Market. Home Office Online Report 05/03.

Dustmann, C., T. Frattini and I. Preston (2007). A Study of the Migrant Workers and the National Minimum Wage and Enforcement Issues. Research Report for the Low Pay Commission. University College London.

Fearon, J. D., and D. D. Laitin (2000). 'Violence and the Social Construction of Ethnic Identity'. International Organization, 54: 845-877.

Filer, R. K. (1992). 'The Effect of Immigrant Arrivals on Migratory Patterns of Native Workers', in: G. J. Borjas and R. B. Freeman (eds.), Immigration and theWorkforce: Economic Consequences for the United States and Source Areas, Chicago: University of Chicago Press. 245-269.

Friedberg, R. M. (2001). 'The Impact of Mass Migration on the Israeli Labour market'. Quarterly Journal of Economics, 116: 1373-1408.

Galor, O. and O. Stark (1991). 'The Probability of Return Migration, Migrants' Work Effort and Migrants’ Performance'. Journal of Development Economics, 35: 399-405.

Grossman, J. B. (1982). 'The Substitutability of Natives and Immigrants in Production'. The Review of Economics and Statistics, 64: 596-603.

Guiso, L., P. Sapienza, and L. Zingales (2006). Does Culture Affect Economic Outcomes? NBER Working Paper No. 11999.

Gustafsson, B. and M. Johansson (1999). 'In Search of Smoking Guns: What Makes Income Inequality Vary over Time in Different Countries?'. American Sociological Review, 64: 585605

Hamermesh, D. S. (1993). Labour Demand. Princeton, New Jersey: Princeton University Press.

Hunt, J. (1992). 'The Impact of the 1962 Repatriates from Algeria on the French Labour Market'. Industrial and Labour Relations Review, 45: 556 - 572. 
ILO (1990). International Standard Classification of Occupations (ISCO-88). International Labour Office. Geneva 1990.

Kahanec, M. 2007. Ethnic Competition and Specialization. IZA Discussion Paper No. 3167.

Kahanec, M. and K. F. Zimmermann (2008). Migration, the Quality of the Labour Force and Economic Inequality, IZA Discussion Paper No. 3560.

Katz, L. F. and K. M. Murphy (1992). 'Changes in Relative Wages, 1963-1987: Supply and Demand Factors'. The Quarterly Journal of Economics, 107: 35-78.

Kuran, T. (1998). 'Ethnic Norms and their Transformation Through Reputational Cascades'. Journal of Legal Studies, 27: 623-659.

LaLonde, R. J. and R. H. Topel (1992). 'The Assimilation of Immigrants in the U.S. Labor Market', in: G. J. Borjas and R. B Freeman (eds.), Immigration and the Work Force: Economic Consequences for the United States and Source Areas. Chicago: University of Chicago Press.

Lipton, M. (1977). Why Poor People Stay Poor: Urban Bias in Developing Countries. London: Temple Smith.

Lipton, M. (1980). 'Migration from Rural Areas of Poor Countries: The Impact on Rural Productivity and Income Distribution'. World Development, 8: 1-24.

Mason, P. L. (2004). 'Annual Income, Hourly Wages, and Identity among Mexican-Americans and other Latinos'. Industrial Relations, 43: 817-834.

McKenzie, D. and H. Rapoport (2006). 'Network Effects and the Dynamics of Migration and Inequality: Theory and Evidence from Mexico'. Journal of Development Economics, forthcoming.

Nekby, L. and M. Rödin (2007). Acculturation Identity and Labour Market Outcomes. IZA Discussion Paper No. 2826

Orrenius, P.M. and M. Zavodny (2007). 'Does Immigrant Affect Wages? A Look at OccupationalLevel Evidence'. Labour Economics, 14: 757-773.

Ottaviano, G.I.P. and G. Peri (2006). 'The Economic Value of Cultural Diversity: Evidence from US Cities'. Journal of Economic Geography, 6: 9-44.

Parasnis, J., D. Fausten and R. Smyth (2006). 'The Impact of Immigration on Native Workers in Australia'. Australian Economic Papers, forthcoming.

Pischke J. S., Velling J. (1997). 'Employment Effects of Immigration to Germany: an Analysis Based on Local Labour Markets'. The Review of Economics and Statistics, 79: 594-604.

Roy, A. D. (1951). 'Some Thoughts on the Distribution of Earnings'. Oxford Economic Papers. 3: 135-146.

Roy, A. S. (1987). 'An Analysis of Substitutability and Complementarity of Immigrants and Canadian-Born Workforce'. Labour Market Bulletin, 4:5-11. 
Roy, A. S. (1997). 'Job Displacement Effects of Canadian Immigrants by Country of Origin and Occupation'. International Migration Review, 31: 150-61.

Sapir, A., P. Aghion, G. Bertola, M. Hellwig, J. Pisani-Ferry, D. Rosati, J. Viñals, H. Wallace, M. Buti, M. Nava and P. M. Smith (2004). An Agenda for a Growing Europe: The Sapir Report, Oxford: Oxford University Press.

Schmidt, C.M., A. Stilz, and K.F. Zimmermann (1994). 'Mass Migration, Unions, and Government Intervention'. Journal of Public Economics, 55: 185-201.

Stahl, C. (1982). 'Labour Emigration and Economic Development'. International Migration Review, 16: 869-899.

Stark, O., J. E. Taylor and S. Yitzhaki (1986). 'Remittances and Inequality'. Economic Journal, 96: 722-740.

Stark, O., J. E. Taylor and S. Yitzhaki (1988). 'Migration, Remittances and Inequality: A Sensitivity Analysis Using the Extended Gini Index'. Journal of Development Economics, 28: 309-322.

Taylor, J.E. (1992). 'Remittances and Inequality Reconsidered: Direct, Indirect, and Intertemporal Effects'. Journal of Policy Modelling, 14: 187-208.

Topel, Robert H. (1994) 'Regional Labour Markets and the Determinants of Wage Inequality'. The American Economic Review, Papers and Proceedings of the Hundred and Sixth Annual Meeting of the American Economic Association, 84: 17-22.

UNESCO (1997). International Standard Classification of Education. ISCED 1997. http://portal.unesco.org/education/en/files/9405/10371902320ISCED_A word.doc/ISCED A \%2Bword.doc, retrieved on 01/29/2008.

Wheatly Price, S. (1999). 'The employment adjustment of male immigrants in England'. Journal of Population Economics. 14: 193-220.

Winkelmann, R. and K. F. Zimmermann (1993). 'Ageing, Migration and Labour Market', in: P. Johnson and K. F. Zimmermann (eds.), Labour Markets in Ageing Europe. Cambridge: Cambridge University Press. 255-283.

Zimmermann, K. F. (2005a). 'European Labour Mobility: Challenges and Potentials'. De Economist, 153: $425-450$.

Zimmermann, K. F. (2005b). European Migration: What Do We Know? Oxford/New York: Oxford University Press.

Zimmermann, K. F. (2007). 'Migrant Ethnic Identity: Concept and Policy Implications'. Ekonomia, The Cyprus Economic Society Annual Lecture in Economics 2007. Forthcoming.

Zlotnik, H. (1999). 'Trends of International Migration since 1965: What Existing Data Reveal'. International Migration, 37: 21-61.

Zorlu, A. and J. Hartog (2005). 'The Effect of Immigration on Wages in Three European Countries'. Journal of Population Economics, 18:113-151. 
Table 1. Share of foreign population and the Gini coefficient

\begin{tabular}{|c|c|c|}
\hline Country & $\begin{array}{c}\text { Foreign } \\
\text { population }\end{array}$ & $\begin{array}{c}\text { Gini } \\
\text { coefficient }\end{array}$ \\
\hline \multicolumn{3}{|l|}{ New World: } \\
\hline Australia & 23.3 & 30.9 \\
\hline Canada $^{(\mathrm{e})}$ & 17.5 & 29.1 \\
\hline United States & 11.8 & 46.2 \\
\hline \multicolumn{3}{|l|}{ Western Europe } \\
\hline Austria $^{(a)}$ & 8.8 & 23.7 \\
\hline Belgium $^{(a)}$ & 8.2 & 29.3 \\
\hline Germany & 8.9 & 31.7 \\
\hline Greece & 7.0 & 32.3 \\
\hline Denmark & 4.9 & 39.0 \\
\hline Finland & 2.0 & 30.2 \\
\hline France $^{(\mathrm{c})}$ & 5.6 & 27.0 \\
\hline Ireland $^{(a)}$ & 4.0 & 28.9 \\
\hline Italy & 2.6 & 36.4 \\
\hline Luxembourg $^{(a)}$ & 37.5 & 26.6 \\
\hline The Netherlands & 4.3 & 27.0 \\
\hline Norway & 4.3 & 27.0 \\
\hline Portugal $^{\text {(a) }}$ & 3.4 & 37.1 \\
\hline Spain & 3.1 & 31.0 \\
\hline Sweden & 5.3 & 25.7 \\
\hline Switzerland & 19.9 & 30.9 \\
\hline United Kingdom & 4.5 & 35.0 \\
\hline \multicolumn{3}{|l|}{ Post-transition: } \\
\hline Czech Republic & 2.3 & 27.3 \\
\hline Hungary & 1.1 & 38.6 \\
\hline Poland & 0.1 & 34.9 \\
\hline Slovakia & 0.5 & 26.0 \\
\hline \multicolumn{3}{|l|}{ Other OECD } \\
\hline Japan $^{(\mathrm{d})}$ & 1.2 & 31.9 \\
\hline Korea $^{(d)}$ & 0.3 & 37.2 \\
\hline Mexico $^{(\mathrm{b})}$ & 0.4 & 53.5 \\
\hline
\end{tabular}

Notes: Data on Gini coefficients are from the WIID 2007 database. Foreign population as a share of total population; the OECD.Stat database. 2002 data, ${ }^{(a)} 2001,{ }^{(b)} 2000,{ }^{(c)} 1999,{ }^{(d)} 1998,{ }^{(e)} 1996$. No data for Iceland, New Zealand, and Turkey. 
Table 2. Labour market participation rates of natives, immigrants, and skill groups

\begin{tabular}{|c|c|c|c|c|c|c|c|c|c|c|c|c|c|c|c|c|}
\hline & EU25 & AT & $\mathrm{BE}$ & DE & DK & ES & FI & FR & GR & IE & IT & LU & NL & PT & SE & UK \\
\hline Natives & 56.49 & 58.62 & 56.66 & 58.09 & 66.28 & 51.89 & 63.26 & 53.65 & 48.32 & 59.07 & 45.29 & 47.42 & 76.17 & 56.88 & 78.45 & 61.07 \\
\hline rants $10+$ & 60.73 & 59.61 & 51.61 & 47.92 & 76.31 & 61.02 & 72.63 & 50.25 & 68.23 & 62.52 & 59.58 & 58.41 & 69.43 & 72.62 & 73.82 & 55.71 \\
\hline $\begin{array}{l}\text { Imm } \\
\text { Educ }\end{array}$ & 57.14 & 60.14 & 54.12 & 51.29 & 74.83 & 72.52 & 67.84 & 50.98 & 67.90 & 68.79 & & 64.08 & 68.10 & 72.00 & 71.62 & 60.53 \\
\hline Hig & .00 & 7.00 & 80.01 & 73.61 & 83.18 & 80.70 & 81.16 & 75.22 & 80.22 & & 75.7 & 76.33 & 86.77 & 84.04 & 88.56 & 89.94 \\
\hline Med & 68.42 & 66.49 & 64.82 & 61.72 & 72.59 & 65.18 & 73.25 & 64.36 & 62.31 & 70.22 & 65.33 & 55.06 & 80.18 & 64.22 & 82.57 & 80.00 \\
\hline Low & 38.00 & 35.49 & 34.60 & 36.28 & 41.30 & 40.95 & 37.53 & 34.74 & 34.39 & 40.69 & 31.63 & 37.29 & 61.06 & 53.84 & 57.76 & 57.09 \\
\hline
\end{tabular}

Notes: Own calculations using data from the EU Labour Force Survey for civilians over 14 years of age. The values for the EU cover all the 25 member states of the European Union in 2005 except for Malta for which no data is available. Immigrants denotes people who were not born in the respective country. Immigrants 10+ are those immigrants who have been in the respective country for at least 10 years. Natives are those born to mothers residing in the respective country. High level of education includes ISCED 5 and 6 levels. ISCED 5 denotes first stage tertiary programmes having an educational content more advanced than those offered by secondary levels. They do not lead to the award of an advanced research qualification and must have a cumulative duration of at least two years. ISCED 6 denotes second stage tertiary education leading to an advanced research qualification and requiring original research contribution in the form of a thesis or dissertation. Medium level of education includes ISCED 3 and 4 levels, which denote education that typically begins at the end of full-time compulsory education and involves higher qualification and specialization than the ISCED 2 level. ISCED 3 level education is often designed to provide direct access to ISCED 5. ISCED 4 serve to broaden the knowledge achieved in ISCED 3 but are not regarded as tertiary. Low level of education includes ISCED 0,1 , and 2 levels. These include pre-primary, primary, and lower secondary or second stage of primary education. The end of ISCED 2 often coincides with the end of compulsory schooling where it exists. For further details see UNESCO (1997).

Table 3. Unemployment rates of natives, immigrants, and skill groups

\begin{tabular}{|c|c|c|c|c|c|c|c|c|c|c|c|c|c|c|c|c|}
\hline & EU25 & AT & $\mathrm{BE}$ & $\mathrm{DE}$ & DK & ES & FI & FR & GR & IE & IT & LU & NL & PT & SE & UK \\
\hline Natives & 7.32 & 3.80 & 7.42 & 9.25 & 5.47 & 8.91 & 6.51 & 9.11 & 9.44 & 4.07 & 7.81 & 3.48 & 3.30 & 7.21 & 5.62 & 4.55 \\
\hline Immigrants $10+$ & 9.64 & 8.20 & 14.79 & 13.91 & 5.65 & 9.91 & 10.77 & 13.76 & 11.14 & 5.30 & 9.15 & 4.08 & 7.25 & 8.31 & 9.81 & 6.19 \\
\hline Immigrants & 10.81 & 9.70 & 16.47 & 16.45 & 9.35 & 11.01 & 14.54 & 15.97 & 10.35 & 6.20 & 11.27 & 5.41 & 8.52 & 9.11 & 12.03 & 7.64 \\
\hline Education: & & & & & & & & & & & & & & & & \\
\hline High & 4.42 & 2.29 & 4.78 & 5.03 & 5.04 & 6.62 & 3.31 & 6.54 & 7.79 & 2.47 & 6.52 & 3.43 & 2.29 & 6.50 & 4.17 & 2.54 \\
\hline Medium & 7.67 & 4.11 & 8.40 & 10.22 & 5.38 & 8.59 & 7.35 & 9.13 & 11.99 & 4.02 & 7.56 & 3.90 & 3.33 & 8.19 & 6.01 & 5.16 \\
\hline Low & 10.49 & 8.36 & 14.18 & 18.10 & 8.15 & 10.84 & 11.21 & 14.19 & 7.86 & 6.66 & 8.99 & 5.95 & 5.81 & 7.29 & 11.54 & 8.94 \\
\hline
\end{tabular}

Notes: See Table 2. 
Table 4. Occupational attainment of natives, immigrants, and skill groups

\begin{tabular}{|c|c|c|c|c|c|c|c|c|c|c|c|c|c|c|c|c|}
\hline & EU25 & AT & $\mathrm{BE}$ & $\mathrm{DE}$ & DK & ES & FI & FR & GR & IE & IT & LU & NL & PT & SE & UK \\
\hline Natives & 39.02 & 38.18 & 45.58 & 45.12 & 46.05 & 32.79 & 43.86 & 39.95 & 33.14 & 38.41 & 39.38 & 46.85 & 48.25 & 24.41 & 44.65 & 40.73 \\
\hline $\mathrm{Imm}$ & 36.58 & 25.13 & 42.46 & 30.68 & 46.78 & 33.99 & 39.31 & 35.46 & 14.57 & 48.58 & 32.92 & 35.24 & 43.70 & 39.61 & 38.58 & 49.69 \\
\hline $\begin{array}{l}\text { Imm } \\
\text { Edu }\end{array}$ & 33.36 & 26.07 & 42.56 & 30.02 & 40.83 & 12.02 & 41.23 & 34.24 & 9.42 & 36.58 & 23.74 & 42.59 & 41.88 & 30.09 & 40.59 & 45.85 \\
\hline $\mathrm{Hiq}$ & 0.15 & 77.65 & 77.64 & 78.20 & 85.88 & 65.98 & 82.93 & 80.21 & 81.72 & & 87.41 & 95.74 & 86.30 & 88.20 & 87.62 & 77.79 \\
\hline Medil & 30.40 & 32.52 & 30.75 & 33.67 & 28.89 & 25.48 & 24.76 & 27.35 & 24.52 & 25.24 & 44.65 & 35.04 & 41.21 & 35.62 & 29.63 & 27.22 \\
\hline Low & 13.14 & 9.76 & 16.48 & 16.80 & 12.85 & 11.20 & 18.46 & 16.40 & 10.05 & 22.07 & 14.54 & 6.19 & 14.72 & 12.46 & 15.12 & 12.70 \\
\hline
\end{tabular}

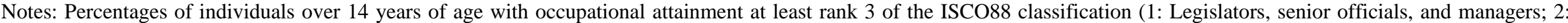

Professionals; 3: Technicians and associated professionals). For details on the ISCO88 classification see ILO (1990). See also Table 2.

Table 5. Educational attainment of natives and immigrants

\begin{tabular}{|c|c|c|c|c|c|c|c|c|c|c|c|c|c|c|c|c|}
\hline & EU25 & $\mathrm{AT}$ & $\mathrm{BE}$ & $\mathrm{DE}$ & DK & ES & FI & FR & GR & IE & IT & LU & NL & PT & SE & UK \\
\hline \multicolumn{17}{|l|}{ Natives } \\
\hline High & 17.33 & 13.18 & 25.95 & 20.18 & 26.75 & 20.58 & 26.32 & 19.53 & 13.28 & 20.85 & 8.43 & 15.44 & 26.13 & 7.72 & 24.73 & 26.30 \\
\hline Medium & 41.03 & 27.82 & 39.68 & 25.14 & 28.63 & 62.33 & 33.53 & 42.81 & 54.95 & 45.73 & 60.44 & 32.92 & 33.18 & 80.83 & 21.78 & 13.97 \\
\hline Low & 41.64 & 59.00 & 34.37 & 54.68 & 44.62 & 17.09 & 40.16 & 37.65 & 31.77 & 33.41 & 31.13 & 51.64 & 40.69 & 11.45 & 53.49 & 59.73 \\
\hline \multicolumn{17}{|c|}{ Immigrants $10+$} \\
\hline High & 19.88 & 12.47 & 20.69 & 16.20 & 34.66 & 25.78 & 24.02 & 16.07 & 16.57 & 33.60 & 12.33 & 19.68 & 23.02 & 22.06 & 24.07 & 31.62 \\
\hline Medium & 39.63 & 40.07 & 51.96 & 41.52 & 23.31 & 48.71 & 28.86 & 59.31 & 44.31 & 33.70 & 47.70 & 45.95 & 31.48 & 53.86 & 25.01 & 19.18 \\
\hline Low & 40.49 & 47.46 & 27.35 & 42.29 & 42.02 & 25.51 & 47.11 & 24.62 & 39.12 & 32.70 & 39.97 & 34.37 & 45.50 & 24.07 & 50.92 & 49.20 \\
\hline \multicolumn{17}{|l|}{ Immigrants } \\
\hline High & 21.94 & 14.18 & 22.94 & 17.36 & 33.86 & 21.33 & 21.80 & 18.06 & 13.72 & 39.79 & 11.72 & 27.51 & 23.28 & 18.83 & 28.50 & 27.70 \\
\hline Medium & 38.32 & 39.46 & 49.46 & 41.73 & 27.89 & 46.76 & 33.74 & 57.47 & 47.74 & 26.58 & 49.80 & 39.93 & 31.69 & 54.72 & 23.86 & 18.45 \\
\hline Low & 39.74 & 46.36 & 27.59 & 40.91 & 38.25 & 31.92 & 44.46 & 24.47 & 38.54 & 33.64 & 38.48 & 32.56 & 45.03 & 26.45 & 47.64 & 53.85 \\
\hline
\end{tabular}

Notes: Percentages of individuals over 14 years of age with High, Medium, and Low educational attainment. See also Table 2. 
Table 6. Immigrant adjustment and selection in Australia

\begin{tabular}{|c|c|c|c|c|c|c|c|c|c|c|}
\hline \multirow[b]{2}{*}{ Months after arrival: } & \multicolumn{3}{|c|}{$\begin{array}{c}\text { Participation rates } \\
\text { LSIA } 1\end{array}$} & \multicolumn{3}{|c|}{$\begin{array}{c}\text { Unemployment rates } \\
\text { LSIA } 1\end{array}$} & \multicolumn{2}{|c|}{$\begin{array}{c}\text { Participation rates } \\
\text { LSIA } 2\end{array}$} & \multicolumn{2}{|c|}{$\begin{array}{c}\text { Unemployment rates } \\
\text { LSIA } 2\end{array}$} \\
\hline & 6 & 18 & 42 & 6 & 18 & 42 & 6 & 18 & 6 & 18 \\
\hline \multicolumn{11}{|l|}{ Skill Stream: } \\
\hline Business skills & 61 & 84 & 88 & 10 & 3 & 1 & 54 & 80 & 8 & 0 \\
\hline Employer nomination scheme & 95 & 99 & 98 & 1 & 3 & 2 & 99 & 100 & 0 & 0 \\
\hline Independent & 88 & 91 & 93 & 25 & 9 & 4 & 89 & 92 & 8 & 7 \\
\hline Skilled Australia Sponsored & 80 & 85 & 90 & 35 & 18 & 10 & 85 & 87 & 21 & 6 \\
\hline \multicolumn{11}{|l|}{ Family Stream: } \\
\hline Family & 49 & 55 & 58 & 38 & 19 & 17 & 53 & 62 & 22 & 13 \\
\hline Humanitarian & 48 & 58 & 67 & 85 & 52 & 33 & 18 & 32 & 71 & 43 \\
\hline
\end{tabular}

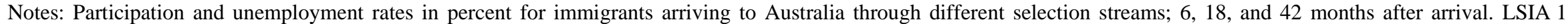

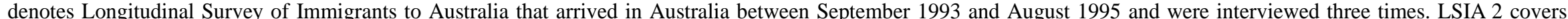

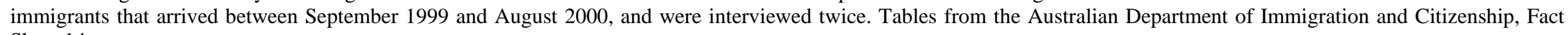
Sheet 14 
Figure 1. Scatter plot of the Gini coefficient as a function of share of foreign labour

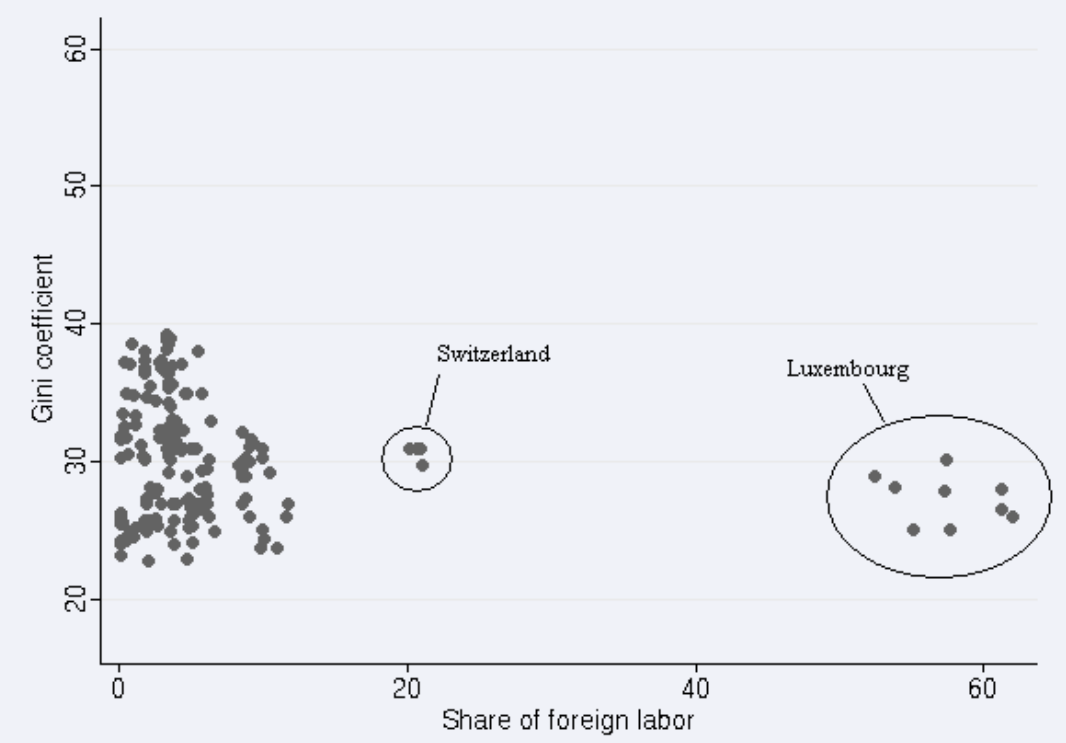

Notes: Data on Gini coefficients are from the WIID 2007 database. Foreign labour force as a share of total labour force; the OECD.Stat database. 1995-2004. Western European OECD members, see Table 1.

Figure 2. Scatter plot of the Gini coefficient as a function of share of foreign labour with a locally weighted line plot.

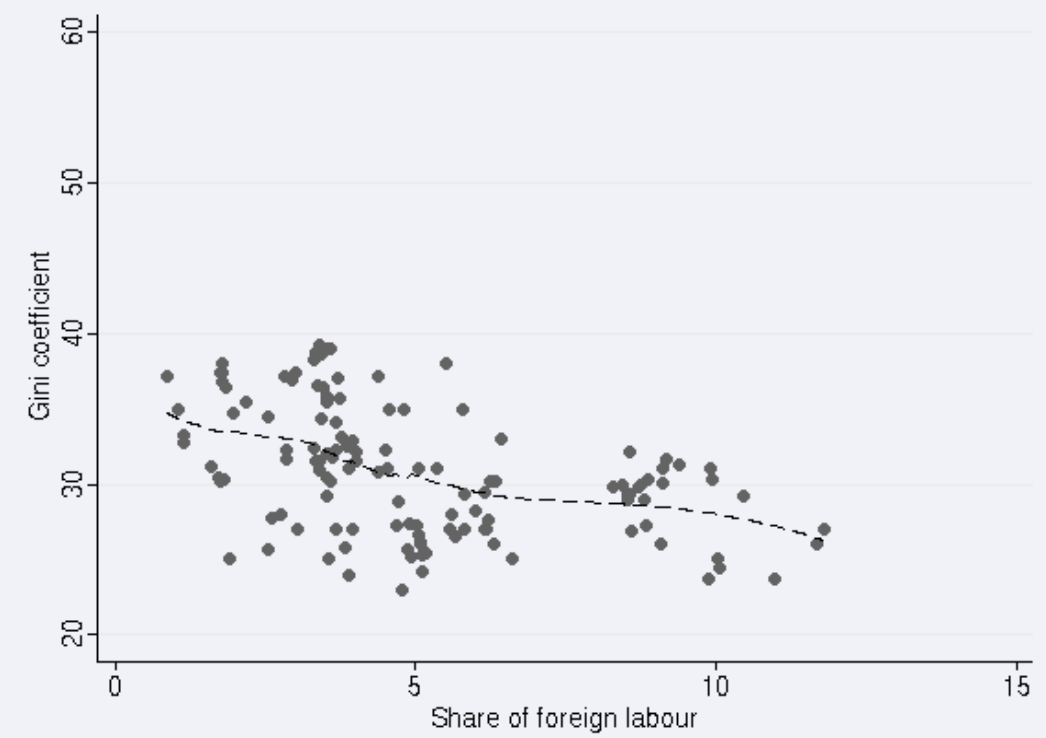

Notes: Western European OECD members, see Table 1, excluding Switzerland and Luxembourg. The dashed line represents a line plot of the nonparametric locally weighted regression of Gini values on the share of foreign labour. See Figure 1 on data sources. 
Figure 3. Gains from immigration: homogenous labour

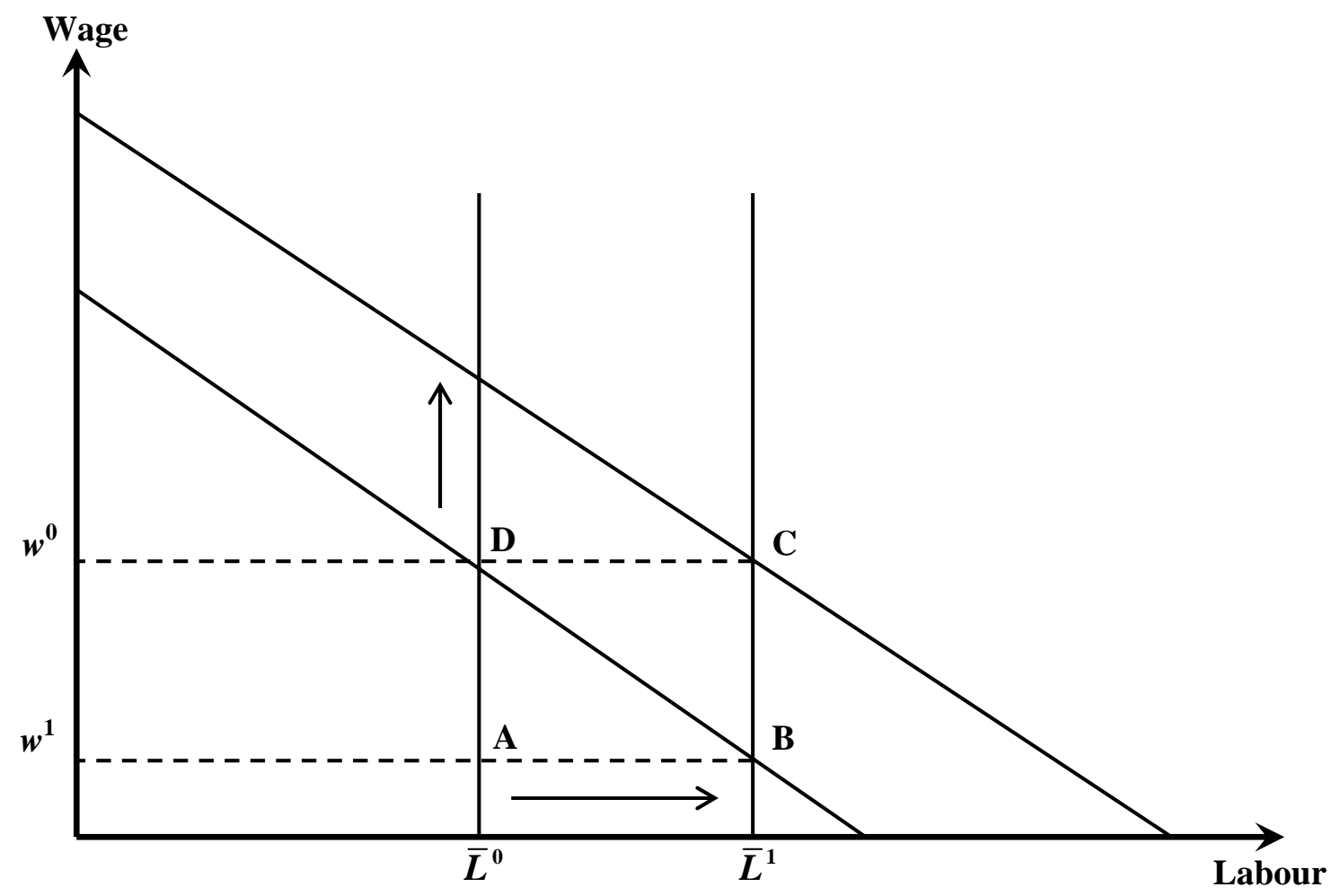


Figure 4. Heterogeneous labour markets: unskilled immigration

(a) Skilled

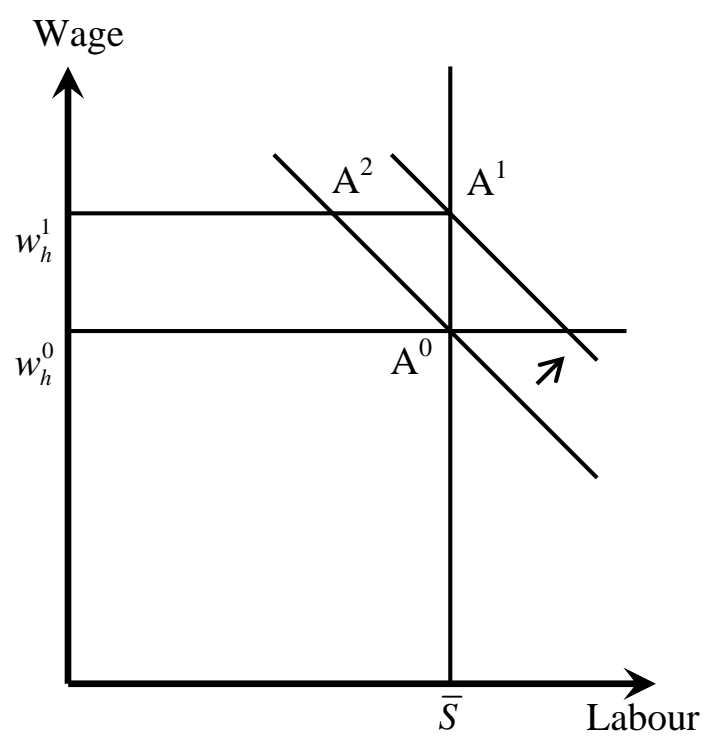

(b) Unskilled

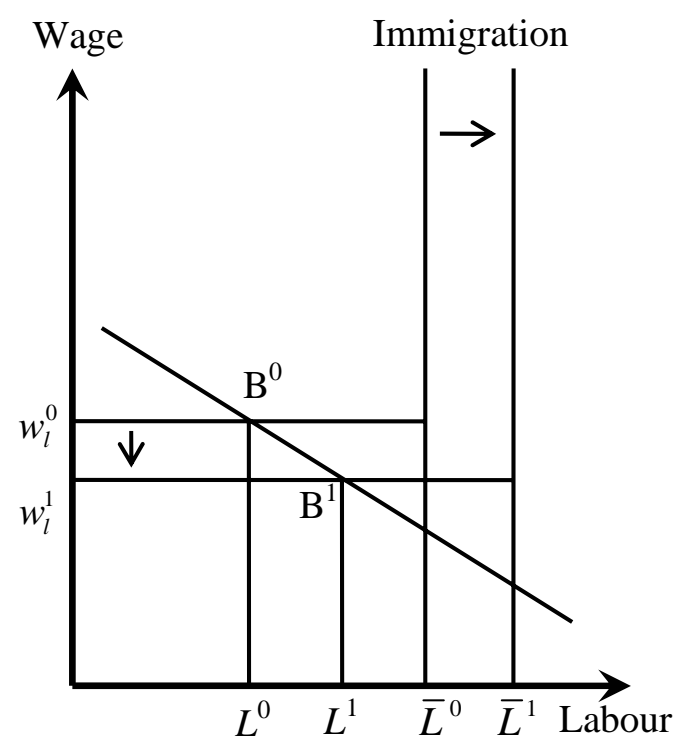


Figure 5. Heterogeneous labour markets: skilled immigration

(a) Skilled

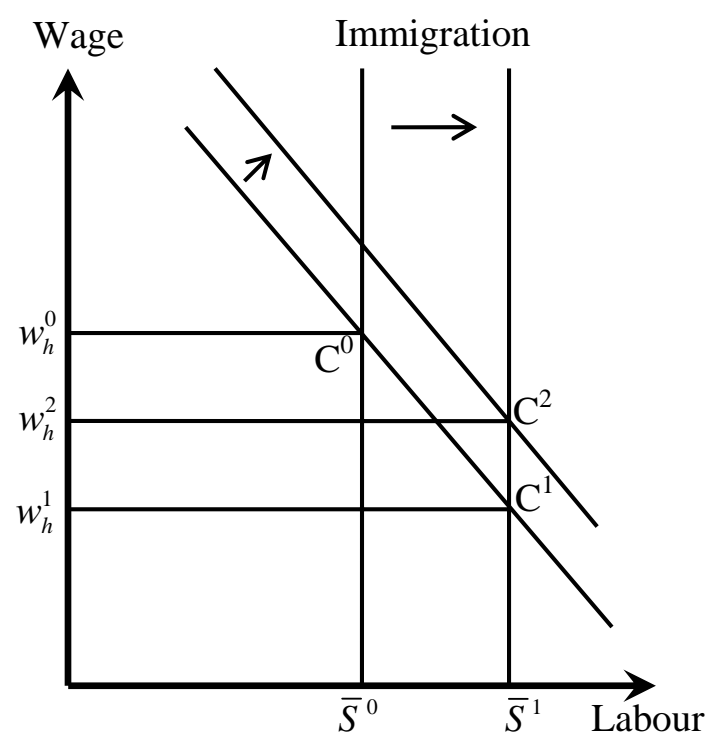

(b) Unskilled

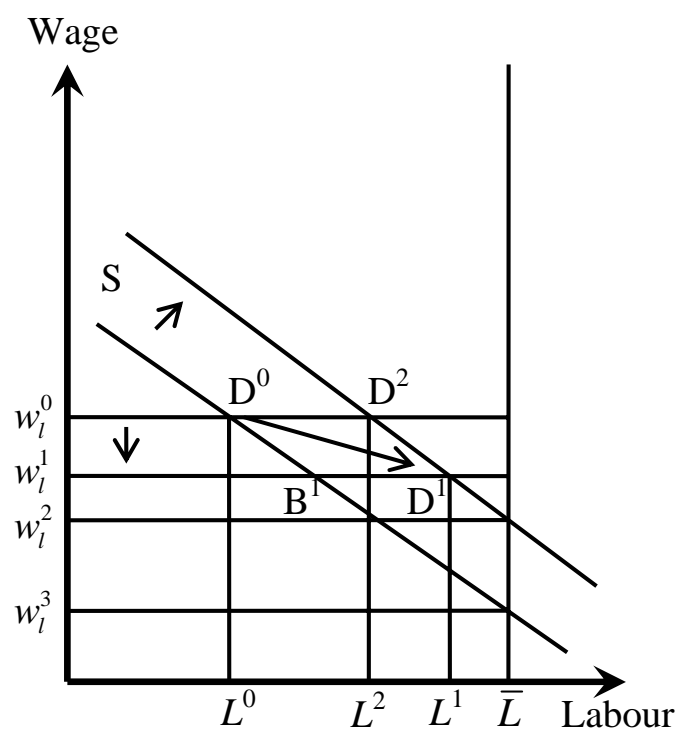


Figure 6. The effects of a rise in the relative wages of the low-skilled on the Gini coefficient by shares of skilled labour

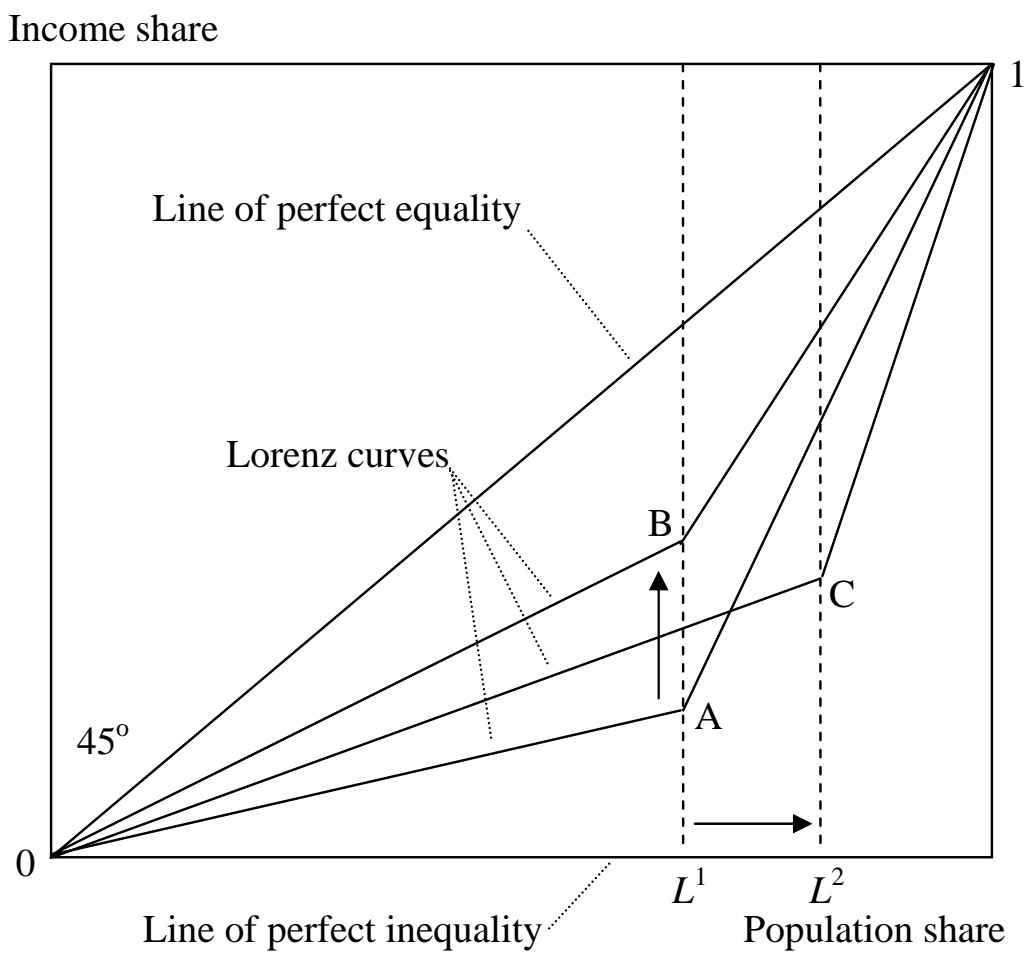

Figure 7. Gini coefficient as a function of the share of skilled workers

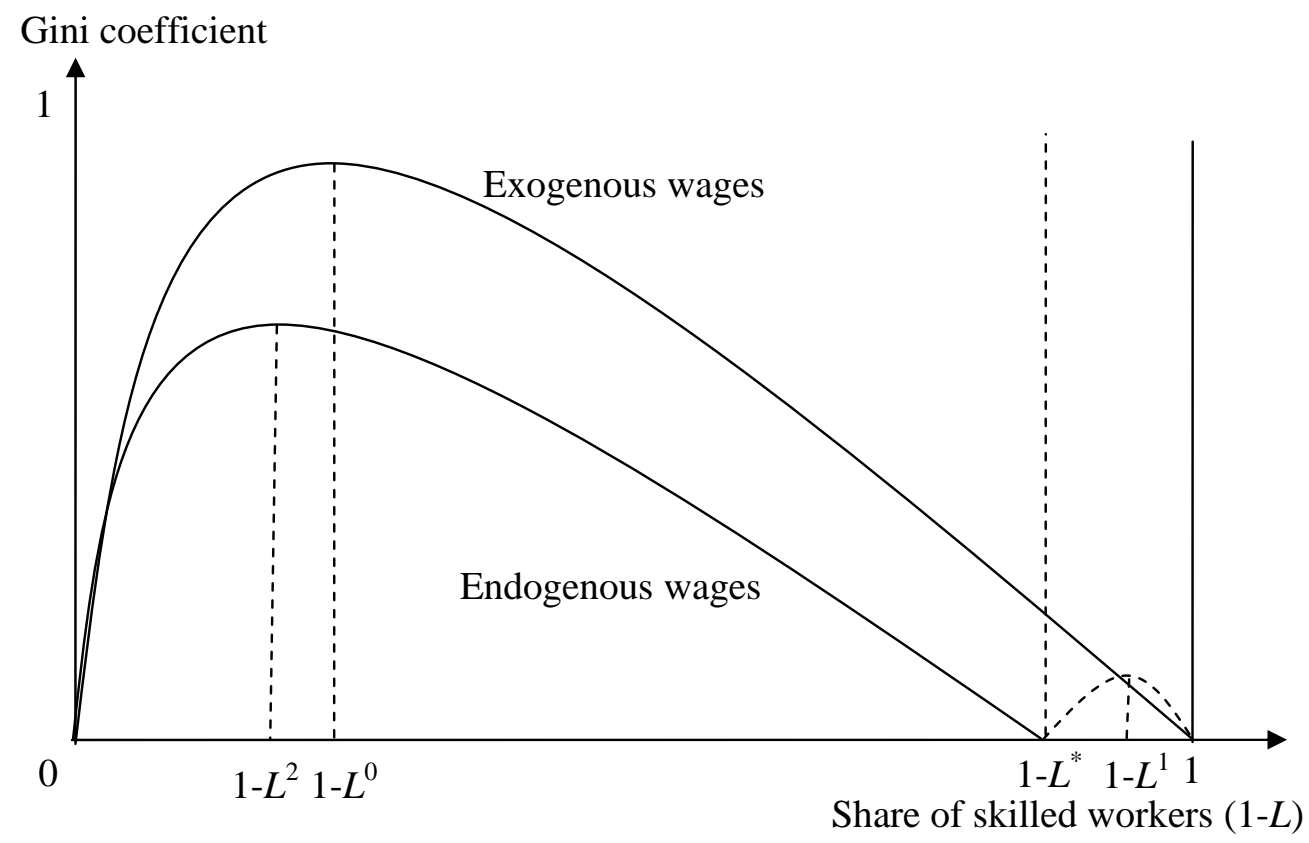


Figure 8: The effects of immigration on the Gini coefficient by shares of skilled labour among natives and immigrants: The case of inflexible wages.

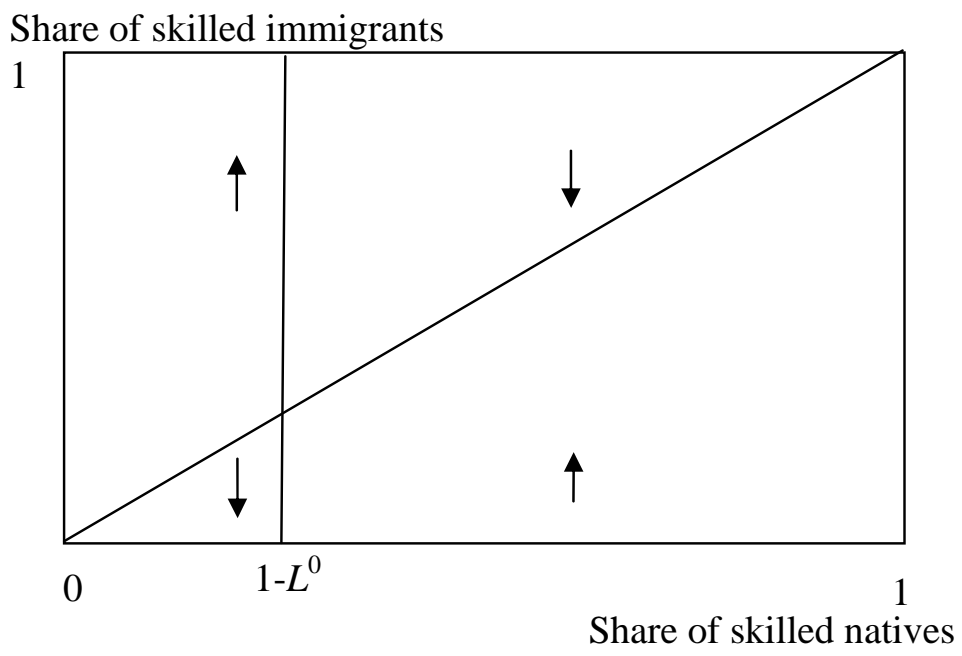

Figure 9: The effects of immigration on the Gini coefficient by shares of skilled labour among natives and immigrants: The case of flexible wages.

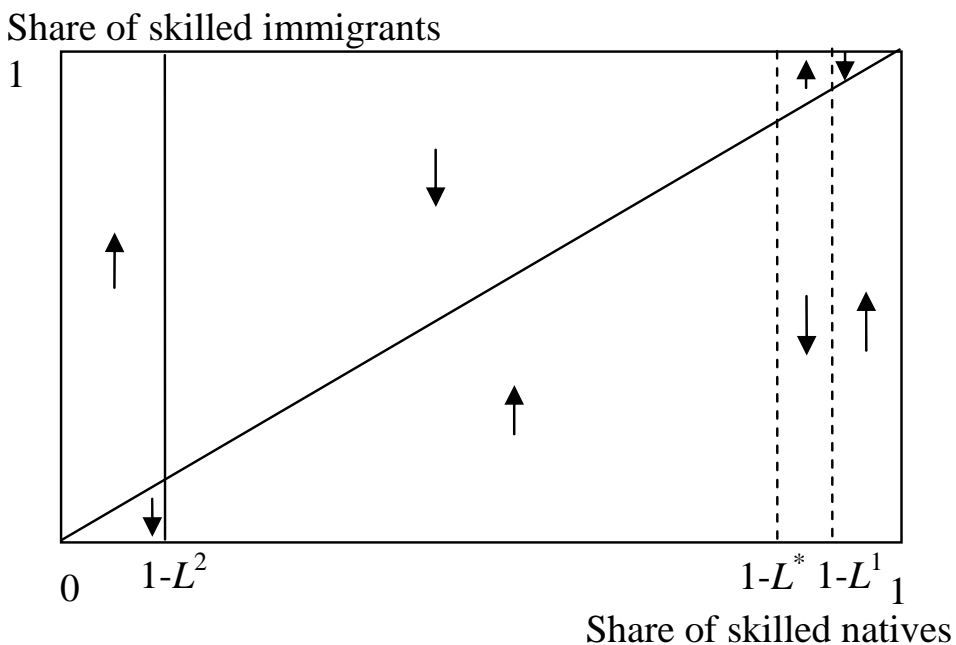


Figure 10: Scatter plot of the Gini coefficient as a function of the share of labour force with upper secondary or higher education

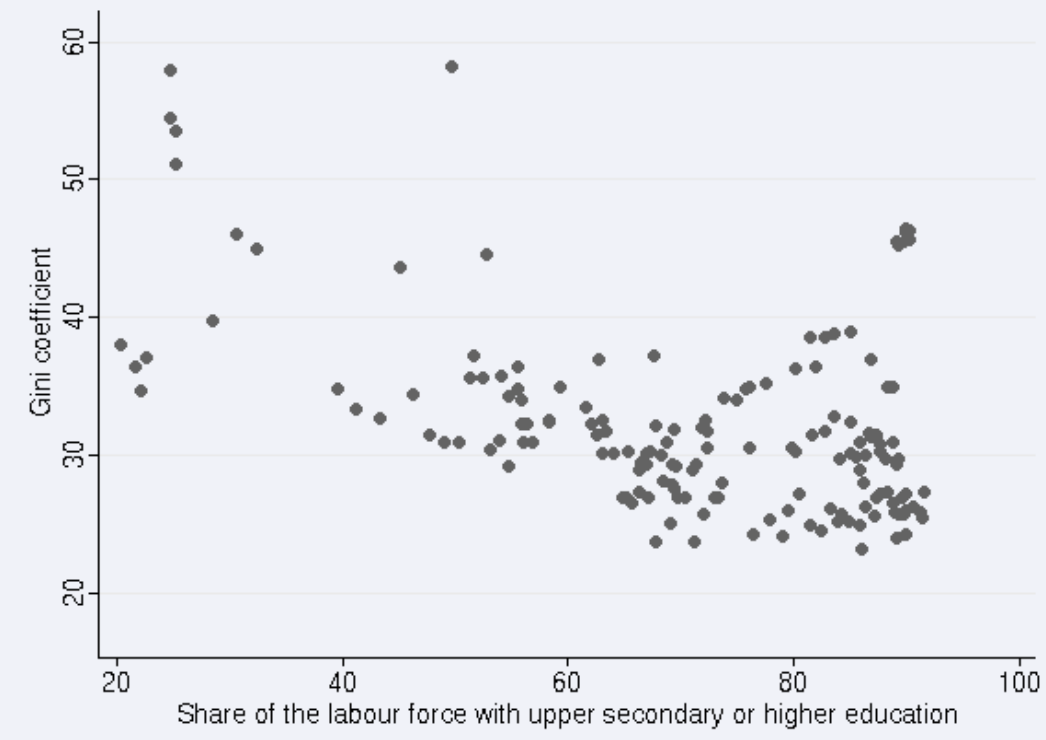

Notes: OECD members except for Iceland. Data on Gini coefficients are from the WIID 2007 database. Data on the shares of labour force with given education are from the OECD Compendium. 1992-2003.

Figure 11: Scatter plot of the Gini coefficient as a function of the share of labour force with post-secondary or higher education

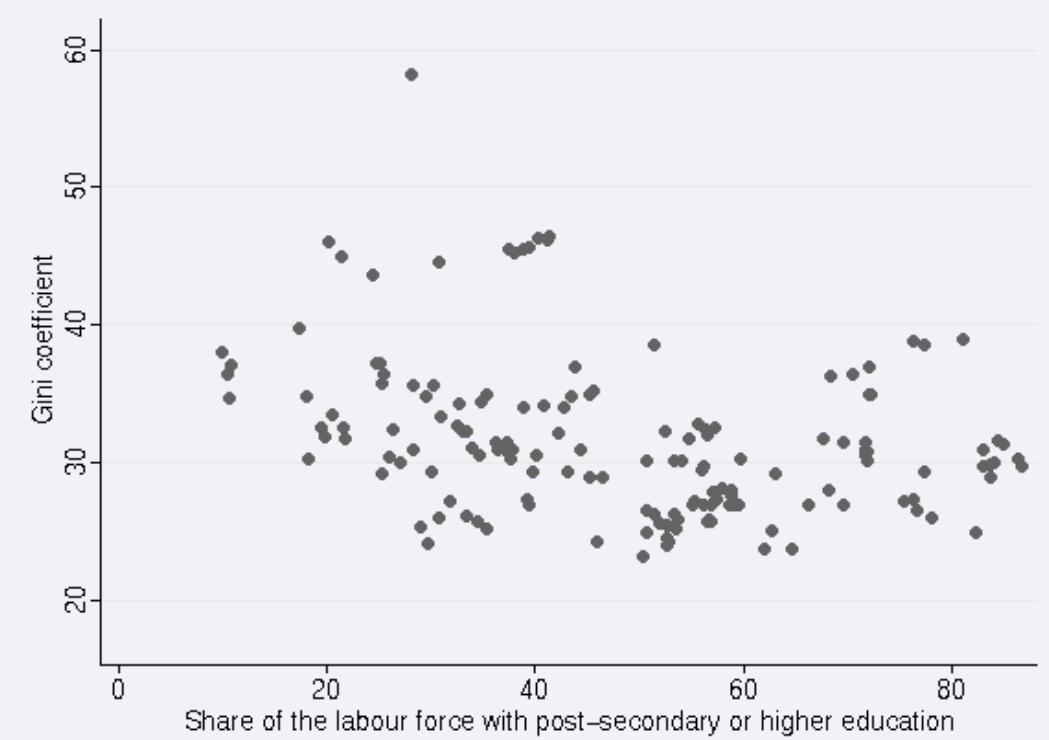

Notes: OECD members except for Iceland and Mexico. Data sources see Figure 10. 1992-2003. 
Figure 12: Line plot of the nonparametric locally weighted regression of the Gini coefficient as a function of the share of labour force with upper secondary or higher education

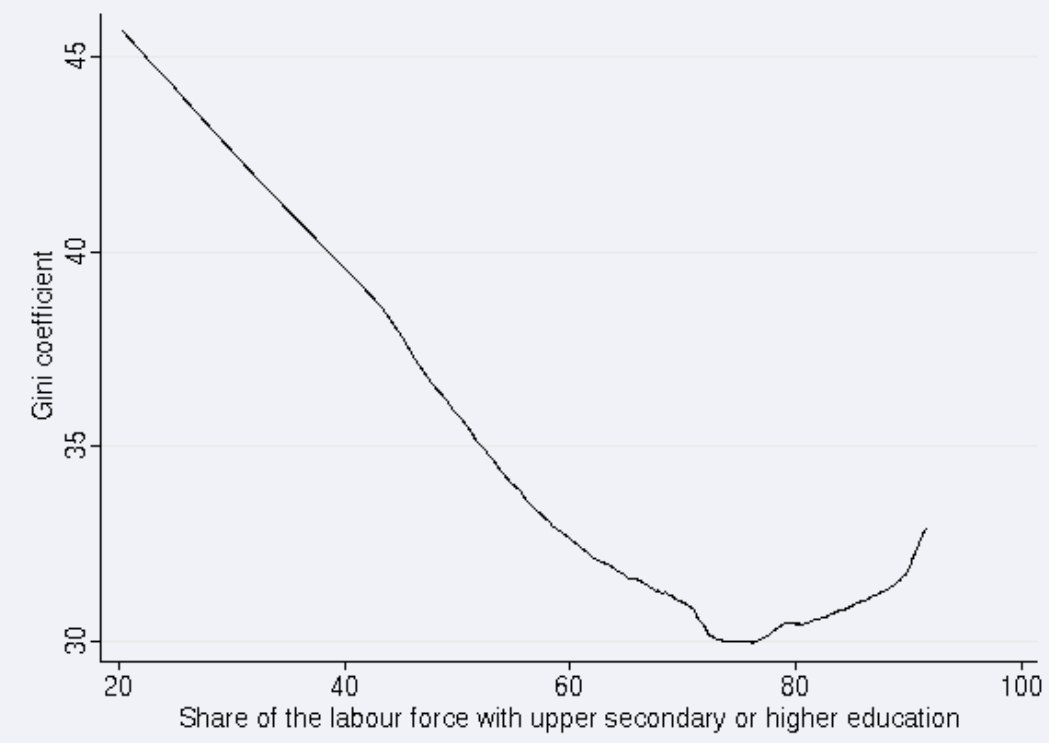

Notes: OECD members except for Iceland. Data sources see Figure 10. 19922003.

Figure 13: Line plot of the nonparametric locally weighted regression of the Gini coefficient as a function of the share of labour force with post-secondary or higher education.

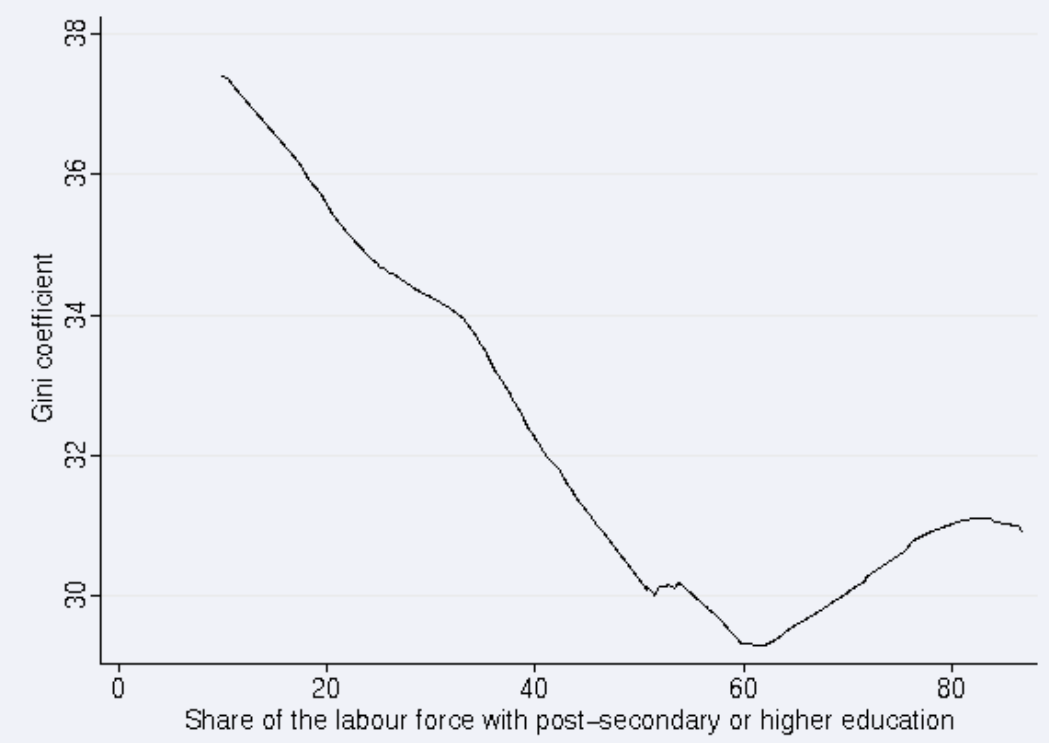

Notes: OECD members except for Iceland and Mexico. Data sources see Figure 10. 1992-2003. 
Figure 14. Immigrant adjustment in the host economy

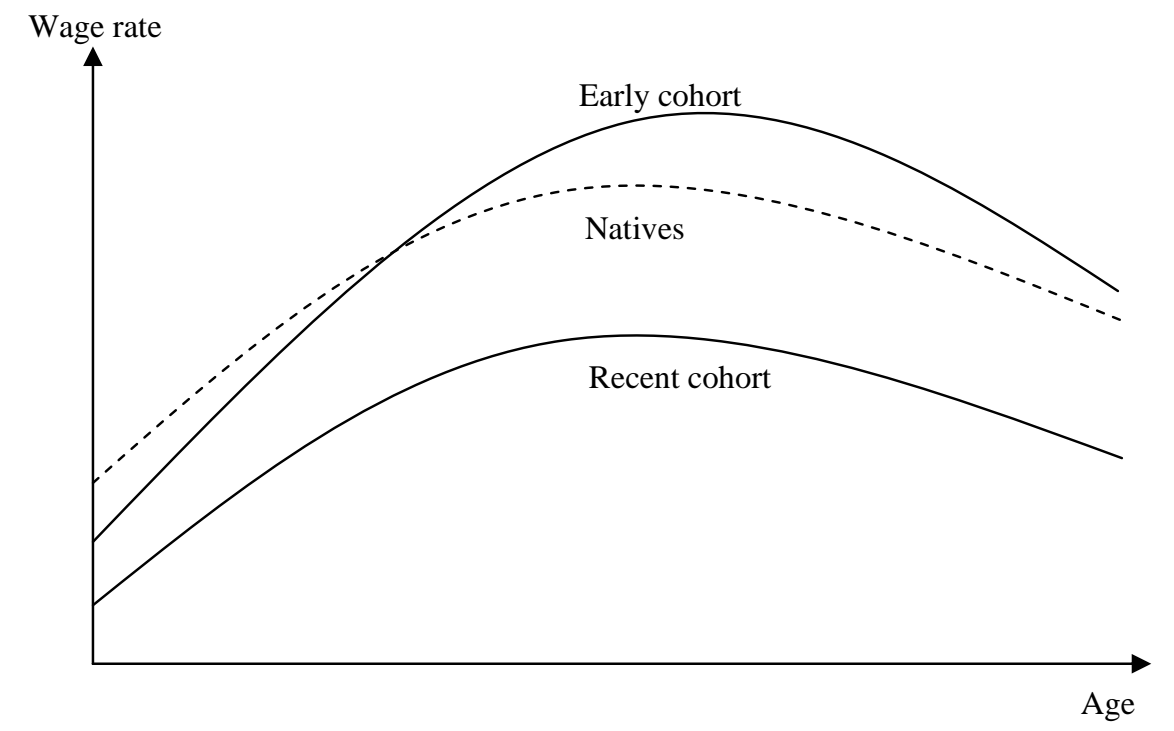

Figure 15. Inequality as a determinant of the migration decision

a)

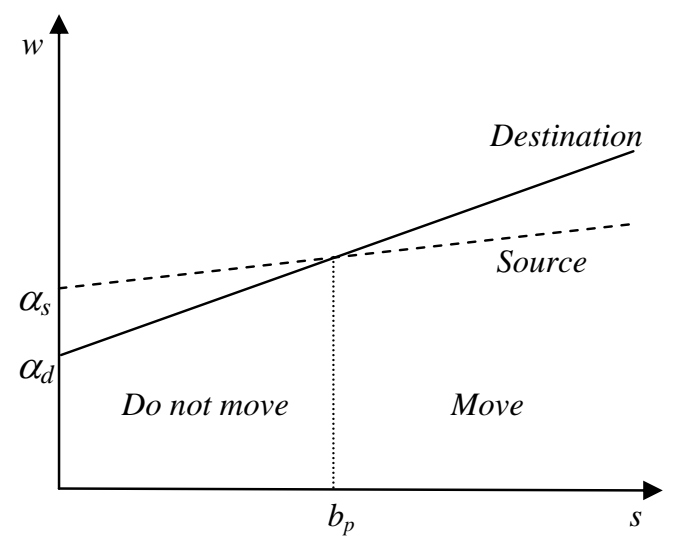

b)

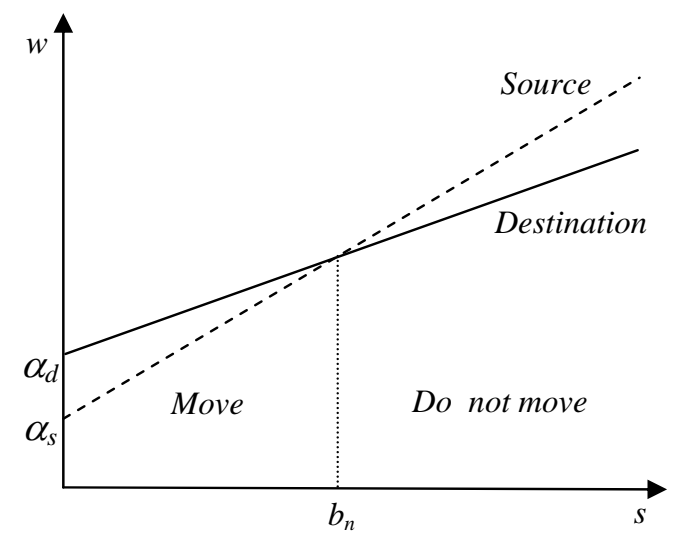


Figure 16. The two-dimensional non-negative ethnosizer

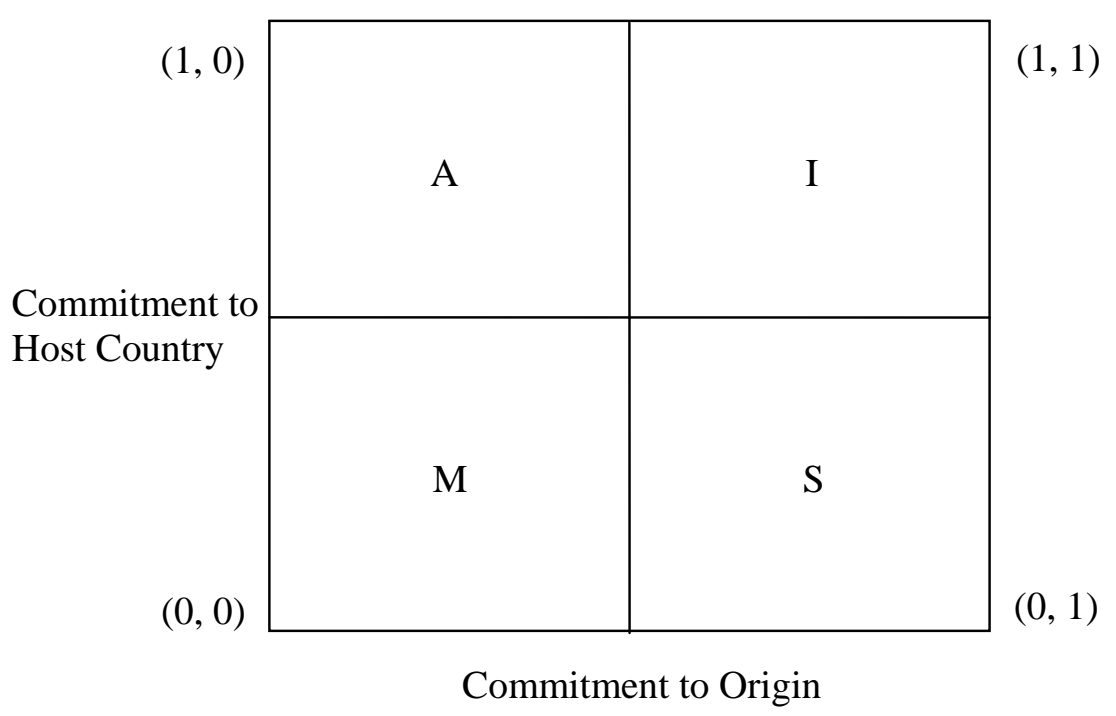

Note: See Constant, Gataullina, and Zimmermann (2006a). 


\section{Appendix: Gini Coefficient and Immigration}

Consider an economy of size 1 with $L$ low-skilled and $S=1-L$ high-skilled workers earning wages $w_{l}$ and $w_{h}$, respectively, as in the main text. We denote $\theta=w_{l} / w_{h}$ and normalize the total income to unity, $w_{l} L+w_{h}(1-L)=1$. The Lorenz curve is then defined by

$$
\begin{aligned}
& z(\lambda)=\frac{\theta \lambda}{\theta L+(1-L)} \text { for } \lambda \in[0, L] \text { and } \\
& z(\lambda)=\frac{\theta L+(\lambda-L)}{\theta L+(1-L)} \text { for } \lambda \in[L, 1]
\end{aligned}
$$

and the Gini coefficient for a given $L$ can be calculated as

$$
G(L)=1-2\left(\int_{0}^{L} \frac{\theta \lambda}{\theta L+(1-L)} d \lambda+\int_{L}^{1} \frac{\theta L+(\lambda-L)}{\theta L+(1-L)} d \lambda\right), \text { which yields } G(L)=\frac{(1-\theta) L(1-L)}{\theta L+(1-L)}
$$

\section{Proposition 1}

For any $L \in[0,1]$ and any given $\theta \in[0,1], d G(L) / d L \underset{<}{<} 0$ whenever $L \frac{\leq}{>} 1 /(1+\sqrt{\theta})$. For any $\theta \in[0,1]$ and any given $L \in[0,1], d G(L) / d \theta<0$.

\section{Proof:}

Straightforward calculus yields $\quad d G(L) / d \theta=\frac{L(L-1)}{(1-L(1-\theta))^{2}} \quad$ holding $\quad L \quad$ constant and $\frac{d G(L)}{d L}=\frac{(1-\theta)(1-L(2-L(1-\theta)))}{(1-L(1-\theta))^{2}}$ holding $\theta$ constant. We immediately see that $d G(L) / d \theta<0$, since the denominator is positive, $L>0$ and $L-1<0$. Similarly, the sign of $d G(L) / d L$ is determined by the sign of $1-L(2-L(1-\theta))$. This is in fact a quadratic formula with roots $1 /(1+\sqrt{\theta})$ and $1 /(1-\sqrt{\theta})$. Only the first one falls into the admissible interval of $L$. We can 
easily see that $1-L(2-L(1-\theta))$ is strictly positive for $L \in[0,1 /(1+\sqrt{\theta}))$ and strictly negative for $L \in(1 /(1+\sqrt{\theta}), 1]$

Now consider the case with endogenous wages such that $\theta=(L /(\alpha(1-L)))^{-\rho}$ where $\rho>0$.

\section{Proposition 2}

For $L \in\left[\alpha^{1-1 / \rho} /\left(1+\alpha^{1-1 / \rho}\right), 1\right)$ the Gini coefficient equals

$$
G(L)=\frac{L(1-L)\left(\alpha-(\alpha(1-L))^{\rho} / L^{\rho}\right)}{\alpha-\alpha L+(\alpha(1-L))^{\rho} / L^{\rho-1}} .
$$

For $L \in\left(0, \alpha^{1-1 / \rho} /\left(1+\alpha^{1-1 / \rho}\right)\right]$ the Gini coefficient equals $-G(L)$.

If $\rho \geq 1, d G(L) / d L>0$ for any $L \in(0,1)$.

For $0<\rho<1$ and $L \in(0,1)$, there exist $L^{1} \in\left(0, \alpha^{1-1 / \rho} /\left(1+\alpha^{1-1 / \rho}\right)\right)$ and $L^{2} \in\left(\alpha^{1-1 / \rho} /\left(1+\alpha^{1-1 / \rho}\right), 1\right)$, such that $d G(L) / d L>0 \quad$ for $\quad L \in\left(L^{1}, L^{2}\right), \quad d G(L) / d L<0 \quad$ for $\quad L \in(0,1)-\left[L^{1}, L^{2}\right] \quad$ and $d G(L) / d L=0$ for $L \in\left\{L^{1}, L^{2}\right\}$. Also, $L^{1}<L^{*}<L^{2}$, where $L^{*}=\alpha^{1-1 / \rho} /\left(1+\alpha^{1-1 / \rho}\right)$

\section{Proof:}

Given $\theta=(L /(\alpha(1-L)))^{-\rho}, L \in\left(\alpha^{1-1 / \rho} /\left(1+\alpha^{1-1 / \rho}\right), 1\right)$ implies $\theta / \alpha=w_{l} / \alpha w_{h}<1$, that is, highskilled workers earn more than low-skilled ones. Then the Lorenz curve is then defined by $z(\lambda)=\frac{\theta \lambda}{\theta L+\alpha(1-L)}$ for $\lambda \in[0, L]$ and $z(\lambda)=\frac{\theta L+\alpha(\lambda-L)}{\theta L+\alpha(1-L)}$ for $\lambda \in[L, 1]$. 
Similarly as above we integrate the Lorenz curve over $\lambda \in[0,1]$ and substitute for $\theta$ to obtain $G(L)=\frac{L(1-L)\left(\alpha-(\alpha(1-L))^{\rho} / L^{\rho}\right)}{\alpha-\alpha L+(\alpha(1-L))^{\rho} / L^{\rho-1}}$ to depict the Gini coefficient in this case and $\frac{d G(L)}{d L}=\frac{\alpha^{2}(1-L)^{2} L^{2 \rho}+L^{2} \alpha^{2 \rho}(1-L)^{2 \rho}-\alpha^{\rho+1} L^{\rho}(1-L)^{\rho}(1-\rho-2 L(1-L))}{\left(\alpha^{\rho}(1-L)^{\rho} L+\alpha(1-L) L^{\rho}\right)^{2}}$.

If $L \in\left(0, \alpha^{1-1 / \rho} /\left(1+\alpha^{1-1 / \rho}\right)\right), \theta / \alpha=w_{l} / \alpha w_{h}>1$ and high-skilled workers earn less than low-skilled ones. The Lorenz curve becomes $z(\lambda)=\frac{\alpha(1-L)}{\theta L+\alpha(1-L)}$ for $\lambda \in[0, L]$ and $z(\lambda)=\frac{\alpha(1-L)+\theta(L-\lambda)}{\theta L+\alpha(1-L)}$ for $\lambda \in[L, 1]$

Integrating the Lorenz curve over $\lambda \in[0,1]$ we obtain that the Gini coefficient in this case is $-G(L) . L=\alpha^{1-1 / \rho} /\left(1+\alpha^{1-1 / \rho}\right)$ is the case of perfect equality.

For $\rho \geq 1$ obviously from the expression for $d G(L) / d L$ it is positive for any $L \in(0,1)$.

For $0<\rho<1$, first note that $G(L)$ and $d G(L) / d L$ are continuous functions for $L \in(0,1)$.

Observe as well that $G(L) \rightarrow 0$ for $L \rightarrow 1$ or $L \rightarrow 0$ and substituting $L=\alpha^{1-1 / \rho} /\left(1+\alpha^{1-1 / \rho}\right)$ into $G(L)$ above yields $G\left(\alpha^{1-1 / \rho} /\left(1+\alpha^{1-1 / \rho}\right)\right)=0$. To see the former, note that $\lim _{L \rightarrow 0^{+}} G(L)=\lim _{L \rightarrow 0^{+}} \frac{L^{1-\rho}(1-L)\left(\alpha L^{\rho}-(\alpha(1-L))^{\rho}\right)}{\alpha-\alpha L+(\alpha(1-L))^{\rho} / L^{\rho-1}}=0$ and $\lim _{L \rightarrow 1^{-}} G(L)=\lim _{L \rightarrow 1^{-}} \frac{L(1-L)^{1-\rho}\left(\alpha-(\alpha(1-L))^{\rho} / L^{\rho}\right)}{\alpha(1-L)^{1-\rho}+\alpha^{\rho} L^{1-\rho}}=0$, where we made use of $0<\rho<1$. 
Furthermore, $d G(L) / d L \rightarrow-\infty$ whenever $L \rightarrow 1$ or $L \rightarrow 0$ and substitution yields $d G(L) / d L>0$ at $L=\alpha^{1-1 / \rho} /\left(1+\alpha^{1-1 / \rho}\right)$. In fact, $d G(L) / d L=\rho \cdot{ }^{32}$ These properties imply that there exists at least one minimum of $G(L)$ on the interval $L \in\left(0, \alpha^{1-1 / \rho} /\left(1+\alpha^{1-1 / \rho}\right)\right)$ and at least one maximum on the interval $L \in\left(\alpha^{1-1 / \rho} /\left(1+\alpha^{1-1 / \rho}\right), 1\right)$, where $d G(L) / d L=0$.

To show the uniqueness of each and the maxima of $d G(L) / d L$, consider the second derivative of $G(L)$. Assume for the moment that $\alpha=1$; we extend the argument to the case where $\alpha>1$ below. First note that

$\frac{d^{2} G(L)}{d L^{2}}=-\frac{(\rho-1)(L(1-L))^{\rho-1}}{\left(-L(1-L)^{\rho}+L^{\rho}(L-1)\right)^{3}}\left(L^{\rho}(1-L)(2 L-\rho)+L(1-L)^{\rho}(2 L+\rho-2)\right)$.

Since the sign of the ratio $\frac{(\rho-1)(L(1-L))^{\rho-1}}{\left(-L(1-L)^{\rho}+L^{\rho}(L-1)\right)^{3}}$ is unambiguously positive for $0<\rho<1$ and $L \in(0,1)$, the sign of the second derivative is the same as the sign of

$-\left(L^{\rho}(1-L)(2 L-\rho)+L(1-L)^{\rho}(2 L+\rho-2)\right)$.

For $0<\rho<1$ and $L \in(0,0.5)$ we can rewrite A1 into the following form $-L^{\rho}(1-L)\left((2 L-\rho)+\left(\frac{L}{1-L}\right)^{1-\rho}(2 L+\rho-2)\right)$. Also, since $2 L+\rho-2<0$ and $L /(1-L)<1$ we can write $(2 L-\rho)+\left(\frac{L}{1-L}\right)^{1-\rho}(2 L+\rho-2) \leq(2 L-\rho)+\frac{L}{1-L}(2 L+\rho-2)=\rho \frac{2 L-1}{1-L} \leq 0$. This result and that $-L^{\rho}(1-L)<0 \quad$ imply $\quad-\left(L^{\rho}(1-L)(2 L-\rho)+L(1-L)^{\rho}(2 L+\rho-2)\right)>0 \quad$ for $\quad 0<\rho<1 \quad$ and

\footnotetext{
32 This result involves tedious algebra. One can show this by evaluating $d G(L) / d L$ at $L^{*}$, simplifying it, and realizing that $d G(L) / d L=1+f(\alpha, \rho)(\rho-1)$ where the term $f(\alpha, \rho)=1$.
} 
$L \in(0,0.5)$. Similarly, rewriting A1 as $-L(1-L)^{\rho}\left(\left(\frac{1-L}{L}\right)^{1-\rho}(2 L-\rho)+(2 L+\rho-2)\right)$ one can show that $-\left(L^{\rho}(1-L)(2 L-\rho)+L(1-L)^{\rho}(2 L+\rho-2)\right)<0$ for $0<\rho<1$ and $L \in(0.5,1)$.

That $d^{2} G(L) / d L^{2}>0$ (and thus $G(L)$ is strictly convex) for any $L \in(0,0.5)$ and $d^{2} G(L) / d L^{2}<0$ (and thus $G(L)$ is strictly concave) for any $L \in(0.5,1), d G(L) / d L<0$ for $L \rightarrow 1$ or $L \rightarrow 0$ and $d G(L) / d L>0$ for $L=\alpha^{1-1 / \rho} /\left(1+\alpha^{1-1 / \rho}\right)=0.5$, and the continuity of $d G(L) / d L$ for $L \in(0,1)$ imply the desired uniqueness of the extrema and the properties of $d G(L) / d L$ for $\alpha=1$.

To extend the argument to the case where $\alpha>1$, note that for $d G(L) / d L=0$ to have at most two solutions within $L \in(0,1)$, it suffices to show that $d^{2} G(L) / d L^{2}=0$ has at most one solution. Note as well that

$$
\begin{aligned}
& \frac{d^{2} G}{d L^{2}}=\frac{L^{\rho-1}(1-L)^{\rho} \alpha^{\rho+1}(\rho-1)}{(L-1)\left((L-1) L^{\rho} \alpha-L(1-L)^{\rho} \alpha^{\rho}\right)^{3}}\left((L-1) L^{\rho} \alpha(-2 L+\rho)+L(1-L)^{\rho} \alpha^{\rho}(-2+2 L+\rho)\right) \text { and } \\
& (L-1) L^{\rho} \alpha(-2 L+\rho)+L(1-L)^{\rho} \alpha^{\rho}(-2+2 L+\rho)=\alpha L^{\rho}(1-L)\left(2 L-\rho+\left(\frac{L}{(1-L) \alpha}\right)^{1-\rho}(2 L+\rho-2)\right) .
\end{aligned}
$$

Thus, we need to show that

$$
H(L)=2 L-\rho+\left(\frac{L}{(1-L) \alpha}\right)^{1-\rho}(2 L+\rho-2)=0
$$

has at most one solution within $L \in(0,1)$ for $\alpha>1$ and $0<\rho<1$. For this to be true it suffices that $H(L)$ is monotonous for $L \in(0,1)$, that is, for $L^{\prime}>L$ it must be that $H\left(L^{\prime}\right)>H(L)$. Consider $L^{\prime}>L$. Then

$$
\begin{aligned}
& 2 L^{\prime}-\rho+\left(\frac{L^{\prime}}{\left(1-L^{\prime}\right) \alpha}\right)^{1-\rho}\left(2 L^{\prime}+\rho-2\right)>2 L-\rho+\left(\frac{L}{(1-L) \alpha}\right)^{1-\rho}(2 L+\rho-2) \text {, which one can rewrite as } \\
& 2\left(L^{\prime}-L\right)+\alpha^{\rho-1}\left(\left(\frac{L^{\prime}}{\left(1-L^{\prime}\right)}\right)^{1-\rho}\left(2 L^{\prime}+\rho-2\right)-\left(\frac{L}{(1-L)}\right)^{1-\rho}(2 L+\rho-2)\right)>0
\end{aligned}
$$


A2 trivially holds whenever

$\left(\left(\frac{L_{1}}{\left(1-L_{1}\right)}\right)^{1-\rho}\left(2 L_{1}+\rho-2\right)-\left(\frac{L_{2}}{\left(1-L_{2}\right)}\right)^{1-\rho}\left(2 L_{2}+\rho-2\right)\right)$

is positive. If A3 is negative, we already know that A2 holds for $\alpha=1$. Since $\alpha^{\rho-1}$ is decreasing for $\alpha \in(1, \infty)$ a negative A3 and the fact that A2 holds for $\alpha=1$ imply that A2 holds for a negative A3 as well.

Therefore, given their continuity, $d^{2} G(L) / d L^{2}=0$ has at most one and $d G(L) / d L=0$ at most two solutions and thus $G(L)$ has at most two interior extrema within $L \in(0,1)$. We already know that there exists at least one minimum of $G(L)$ on $L \in\left(0, \alpha^{1-1 / \rho} /\left(1+\alpha^{1-1 / \rho}\right)\right)$ and at least one maximum on $L \in\left(\alpha^{1-1 / \rho} /\left(1+\alpha^{1-1 / \rho}\right), 1\right)$. Therefore, these extrema are unique and we can denote $L^{1} \in\left(0, \alpha^{1-1 / \rho} /\left(1+\alpha^{1-1 / \rho}\right)\right)$ the minimum and $L^{2} \in\left(\alpha^{1-1 / \rho} /\left(1+\alpha^{1-1 / \rho}\right), 1\right)$ the maximum. Clearly, it also follows that $L^{1}<L^{*}<L^{2}$, where $L^{*}=\alpha^{1-1 / \rho} /\left(1+\alpha^{1-1 / \rho}\right)$ 